\title{
A robust fuzzy possibilistic AHP approach for partner selection in international strategic alliance
}

\author{
Vahid Reza Salamat $^{\text {a }}$, Alireza Aliahmadi ${ }^{*}$, Mir Saman Pishvaee ${ }^{\text {a }}$ and Khalid Hafeez
}

\author{
Article history: \\ Received March 14, 2017 \\ Received in revised format: \\ October 20, 2017 \\ Accepted December 18, 2017 \\ Available online \\ December 19, 2017 \\ Keywords: \\ International Strategic Alliance \\ Resource-Based View \\ Transaction-Cost Theory \\ Fit \\ Robust Programming \\ Interval AHP
}

${ }^{a}$ Department of Industrial Engineering, Iran University of Science and Technology, Tehran, Iran

${ }^{b}$ Department of Progress Engineering, Iran University of Science and Technology, Tehran, Iran

${ }^{c}$ Business \& Management Division, Dundee Business School, University of Abertay, Dundee, United Kingdom

\section{A B S T R A C T}

\begin{abstract}
The international strategic alliance is an inevitable solution for making competitive advantage and reducing the risk in today's business environment. Partner selection is an important part in success of partnerships, and meanwhile it is a complicated decision because of various dimensions of the problem and inherent conflicts of stockholders. The purpose of this paper is to provide a practical approach to the problem of partner selection in international strategic alliances, which fulfills the gap between theories of inter-organizational relationships and quantitative models. Thus, a novel Robust Fuzzy Possibilistic AHP approach is proposed for combining the benefits of two complementary theories of inter-organizational relationships named, (1) Resource-based view, and (2) Transaction-cost theory and considering Fit theory as the perquisite of alliance success. The Robust Fuzzy Possibilistic AHP approach is a novel development of Interval-AHP technique employing robust formulation; aimed at handling the ambiguity of the problem and let the use of intervals as pairwise judgments. The proposed approach was compared with existing approaches, and the results show that it provides the best quality solutions in terms of minimum error degree. Moreover, the framework implemented in a case study and its applicability were discussed.
\end{abstract}

C 2018 by the authors; licensee Growing Science, Canada.

\section{Introduction}

High unpredictability of customer needs and market demands, increasing global competition and environmental uncertainties have made intense pressure on firms; and have convinced them that they cannot internally perform all of their value stream activities. Thus, the firms have encouraged to strategic partnership and alliancing and an increasing growth in partnerships and alliances occurred globally (Gomes et al., 2014; K. Möller et al., 2005), so strategic alliances between firms have evolved as a ubiquitous phenomenon in today's business environment (Gulati, 1998; Wassmer, 2010). Indeed, exponential growth in the number of inter-organizational relationships in present decades convinced the authors to not only discuss strategic alliances, but also to introduce concepts such as "portfolio of

* Corresponding author.

E-mail address: pe@iust.ac.ir (A. Aliahmadi)

(C) 2018 by the authors; licensee Growing Science, Canada. doi: $10.5267 /$ j.dsl.2017.12.002 
alliances" (Wassmer, 2010), strategic nets and networks (Cimon, 2013; Gulati et al., 2000; Möller \& Rajala, 2007; Möller et al., 2005; Möller \& Svahn, 2003; Möller \& Halinen, 1999), "relational view" (Dyer \& Singh, 1998) and "business networks" (Ritter et al., 2004). However, strategic alliances and capability of alliance management can be seen as an important source of competitive advantages (Dyer \& Singh, 1998; Ireland et al., 2002; Leischnig et al., 2014; Schreiner et al., 2009). Despite the increase in the number of strategic alliances, however, studies have shown that there are high failure rates in strategic alliances and approximately $50 \%$ of alliances do not satisfy the initial expectations (Koza \& Lewin, 2000).

Strategic alliances defined as "voluntary arrangements between firms involving exchange, sharing, or co-development of products, technologies, or services" (Gulati, 1998), or as "cooperative relationships driven by a logic of strategic resource needs and social resource opportunities" (Das \& Teng, 2000). Strategic alliances are formed with the aim to improve the effectiveness of performance and the competitive position by sharing and co-utilization of resources (Hitt et al., 2000). Gomes et al. (2014) introduce the thematic area in the strategic alliance research in 22 fields of study: (1) Influential factors on S.A., (2) Choice and evaluation of strategic partner, (3) Choice between M\&A and Alliance, (4) Alliance rationale, (5) Alliance management, (6) Managing communication (7) Managing risk \& opportunism, (8) Trust, control and confidence, (9) Contract \& negotiation, (10) Commitment, (11) Cultural issues, (12) Shape and design, (13) Types of alliance, (14) Alliance portfolio, ownership, and formation, (15) Alliance structures, (16) Network relationships, (17) Specialized areas, (18) Alliance performance, (19) HRM issues, (20) Organizational justice, (21) Leadership and decision making, (22) Knowledge transfer, learning and experience. In this study, the focus was concentrated on the second item: "choice and evaluation of strategic partner." This item is one of the growing trends in the strategic alliance area as introduced by Gomes in their review (Gomes et al., 2014). In addition to the growing trend in academic works, the choice of an appropriate strategic partner has an important role in the success of the alliance. It is more significant when we see that the facts show the high failure rate in the alliances (MacAvoy et al., 1998; Madhok \& Tallman, 1998; Reuer, 1999; Young-Ybarra \& Wiersema, 1999) and non-suitable choice is one the failure reason. Alliance choice is an important and effective decision and received a lot of attention from scholars. However, it is a complex decision because of different aspects of the problem, inherent conflicts between stockholder's preferences and incomplete knowledge of decision makers (DMs). Thus, in this paper the problem of "strategic alliance choice and evaluation" was considered and addressed from a theoretical point of view, into an analytical solution.

The proposed framework consists of a conceptual framework and an analytical approach. In the conceptual framework the assessment criteria and sub-criteria are discussed. The assessment criteria are defined based on theories of inter-organizational relationships, namely: (1) resource-based view (RBV), and (2) transaction-cost theory (TCT) as two complementary theories and (3) fit theory as a perquisite of alliance success. This combination leads to a more comprehensive approach, which can cover more aspects of the problem and has more conformity to the reality. The RBV and TCT are two dominant theories and are two complementary one. Many authors emphasize on the beneficious of a hybrid theory of them, but there is no integrative approach which use of a hybrid of them. In this paper a hybrid of them was used in the conceptual framework as two theories which justifying the value creation in alliances and fit theory is added as perquisite of any alliance success.

In the analytical approach, the evaluation of criteria is performed by a novel "Robust Fuzzy Possibilistic AHP" (RFPA) approach. The AHP approach introduced by Saaty (1977), was based on pairwise comparison of alternatives and is widely used in decision making problems. The interval AHP is one of the major developments, which let the decision makers to provide the interval pair wise judgements for handling DMs' ambiguity. The existing approaches for Interval AHP has some weaknesses in the inconsistent judgements. When the pairwise judgements are not consistent there are no solution rations, which satisfy all of interval constraints and inevitably, some of the solution ratios do not place in the intervals. In the proposed framework, because of the large amounts of pairwise judgements, there is a high probability of inconsistency. In addition, Robust Programming is a novel approach in handling 
uncertainties and imprecise data. Robust Programming is applied in many practical problems and in many MADM/MODM techniques, but there is no robust AHP approach yet. Thus, a Robust Fuzzy Possibilistic AHP approach is proposed to reduce the out of interval degree. The proposed approach is compared with previous models, and the results show that it is the best in terms of interval's satisfaction.

In the rest of the paper, the literature of partner selection in international strategic alliance (ISA) is presented in the Section 2. Strategic precedence of partner selection in ISA is presented in Section 3; the conceptual framework and analytical approach (the proposed Robust Interval AHP approach) is illustrated in Section 4 and 5. The framework implemented and discussed in Section 6. The Section 7 is devoted to conclusion.

\section{Partner selection in international strategic alliance}

Partner selection is an important phase of any inter-organizational collaboration and attracted much attention in academic efforts. A huge part of literature is devoted to partner selection in joint ventures (JV), especially in international joint ventures (IJV). Williams and Lilley (1993) discuss the influencing factors in partner selection in JVs and placed them in different steps of the partner selection process. Luo (1997) provides a strategic viewpoint to partner selection problem in Chinese JVs and examine the role of strategic and organizational traits of local partners. Then, he discusses the partner selection criteria in Chinese JVs. Makino and Beamish (1999) discuss the adaptation of strategies with ownership structures in Japanese JVs. Roy and Oliver (2009) discuss the role of the legal environment in IJV's partner selection. In this stream, there are lots of scientific work which concentrates on the criteria and determinants of partner selection, for example, Islam et al. (2011), Glaister and Buckley (1997) and Roy (2012), furthermore, Salavrakos and Stewart (2006) discuss the association between partner selection criteria and joint venture performance in IJVs. The second huge part of literature is dedicated to partner selection in franchises as an important type of strategic alliance. First of all, Altinay (2006) discusses the partner selection in international franchises. He suggests that both partner and task related criteria should be considered for an effective partner selection. Then, Doherty (2009) provides a case study and proposes a conceptual framework to address strategic and opportunistic aspects of the problem. Brookes and Altinay (2011) discuss the criteria of partner selection from the perspective of both franchisors and franchisees. Furthermore, Altinay et al. (2013) discuss the criteria and process of partner selection in tourism franchises.

In addition to these special parts, partner selection was also discussed in general forms of strategic alliance and more specifically in international strategic alliances. In this way, Todeva and Knoke (2005) provide a review of the academic efforts on the strategic alliance subject and propose insights for future research. Dong and Glaister (2006) evaluate the motives of partners in the formation of international strategic firms. They approach the problem from two perspectives of Chinese firms and foreign firms and rank the motives in each perspective. In this way, Dacin et al. (1997) discuss the criteria in the partner selection process and explore the differences and similarities of the criteria between Korean and US managers. Li and Ferreira (2008) examine multinational corporations (MNC) preference about forming ISA with their previous partners in emerging economies. They find that the US MNCs prefer to ally with their previous partners. They also find that in large institutional distance between partners, selection of prior partners is more probable. Shah and Swaminathan (2008), in an outstanding work, argue that the criteria of partner selection depend on alliance project type. They provide a conceptual framework based on two variables of "process manageability" and "outcome interpretability" and discuss the fact that critical criteria depend on different levels on these two variable. Solesvik and Westhead (2010) tried to examine the partner selection criteria using a multi-case study methodology. They explore the maritime firms in Norway and emphasized on the role of cyclicality in the partner selection process, trust and common strategic goals between partners. Baum et al. (2010) try to provide a model for partner selection in innovation networks with the purpose of learning and innovation. They emphasize on the idea that firm's knowledge should be fit for co-learning and co-innovation. Also, there are various approaches of partner assessment and selection in virtual enterprises, outsourcing and other forms (Büyüközkan \& Görener, 2015; Chang, 2009; Kavčič \& Tavčar, 2008; Wiltshier \& Edwards, 
2014). The analytical tools and mathematical methods are used in the problem of partner selection in strategic alliances. Hajidimitriou and Georgiou (2002) discuss the problem of partner selection in IJV and propose a goal programming model for this problem. They state that the majority of scientific efforts was concerned to criteria of partner selection and development of quantitative models were neglected. Ding and Liang (2005) propose a fuzzy-MCDM approach for partner section. They use fuzzy triangular numbers and the concept of ideal and anti-ideal solutions. Büyüközkan et al. (2008) propose a MCDM approach for partner selection. They use the Fuzzy-AHP for calculation of criteria weights and employ Fuzzy-TOPSIS for evaluating the final rank of each partner. Chen et al. (2008) employ the analytic network process (ANP) approach for weighting of partner selection criteria and try to handle the dynamic aspects of the problem via the ANP method. In a similar way, Wu et al. (2009) propose an ANP approach for partner selection problem and try to consider both tangible/intangible influencing factors of the problem. After that, $\mathrm{Wu}$ et al. (2009) develope an alliance partner selection process and propose a new dynamic analytical tool which employed in suggested process. In compliance with previous works (Chen et al., 2008; Wu et al., 2009), the authors try to combine the ANP approach with fuzzy preference programming. The advantage of the proposed approach is that it can consider the uncertainty of the problem and disagreement between decision makers (Wu et al., 2009). Recently, Sahebi et al. (2015) formulate a lexicographic goal programming approach to the problem of joint venture formation in oilfield projects. They tried to tackle with diverse goals in the problem.

\section{Strategic precedence of partner selection in ISA}

From the resource-based perspective, the firm's resources are the main origin of competitive advantage and foundation of a firm's strategy (Barney, 1991; Wernerfelt, 1984). Also, strategic alliance is an important way to acquire essential resource from the intermediate market (neither market structure nor internal development, merger \& acquisition etc.), and, the formation of a strategic alliance is long-term, strategic decision. Thus, partner selection and alliance formation should be considered as a part of the firm's strategic plan. Inspired from Grant's process of strategy formulation (Grant, 1991), and by incorporating Porter's industry analysis (Porter, 1980) (which was neglected in Grant's process and resource-based perspective), the position of alliance formation/partner selection in the firm's strategy formulation process can be seen as illustrated in Fig 1.

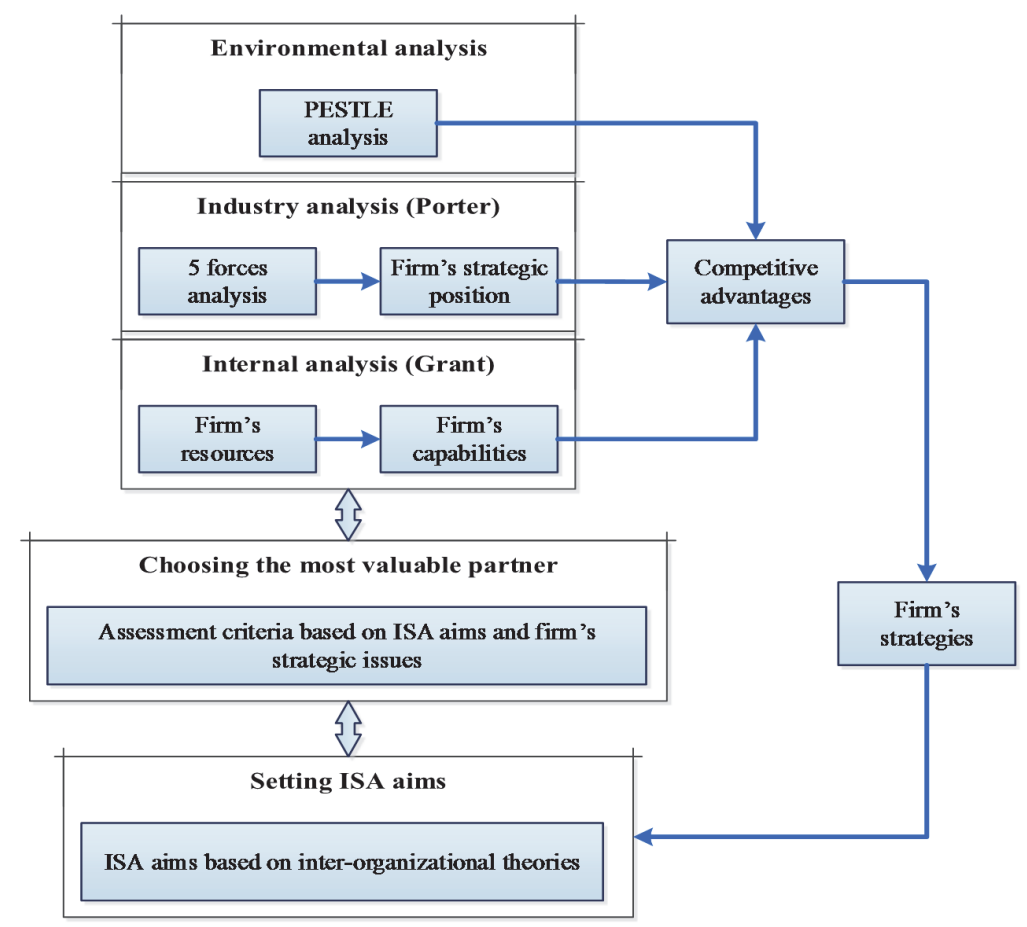

Fig. 1. An overview of the framework 
The procedure organized in three parts, in the first the aim is to determine the business strategy. In this part a combination of porter's competitive strategy (Porter, 1979) and grant's resource-based theory of competitive advantage is employed (Grant, 1991). In the second part, the alliance purposes were determined in relation with business strategy. In the third, a value assessment framework tries to facilitate the selection, governance and management of the alliances.

In the first part, two dominant approaches of strategic planning were employed. The first, the porter's competitive forces emphasize the determination of strategy based on industry (external) analysis, and the second; resource-based view emphasizes on internal analysis of resources and capabilities as the base of competitive advantage. Porter's model (Porter, 2008) tries to analyze the industry and argue that the competitive advantage of a firm arises from industry attractiveness and firm's position. The procedure of this framework started with an analysis of the five competitive forces; namely (1) bargaining power of suppliers, (2) bargaining power of buyers, (3) the threat from new entrants, (4) the threat of substitutes, and (5) intensity of competitive rivalry. The combination of these forces determined the attractiveness of industry, which is the main source of competitive advantage. Grant's framework is based on resource-based view of firm (Grant, 1991). In this part as depicted in Fig 1, the firm's competitive advantage and strategy determined by integration of porter's and grant's approaches, which are representative of external and internal analysis. In the following, the value assessment framework tries to balance between firm's strategies and alliance purposes. After determination of the firm's strategy, the next step is to determine the alliance aims based on firm's strategy, in order to fill the gaps in firm's resources for better accomplishing of strategies. Finally, assessment of partners should be done by the determined aims of the alliance. This framework is an infrastructure for alliance formation/partner selection, which provide a holistic view for managers and clear the roadmap of the firm for the formation of an alliance.

\section{The conceptual framework}

In this part, the assessment criteria are introduced which then will be used in the proposed quantitative model. The assessment criteria are defined based on fundamental alliance theories. In other words, the theories of inter-organizational relationships were reviewed and the assessment criteria were selected based on them (as depicted in Fig 2). In the following, the theories and assessment criteria are described briefly.

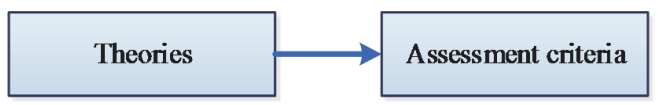

Fig. 2. The relation between theories, aims and assessment criteria

\subsection{The rationale behind value creation through alliances (theories of inter-organizational relationships)}

Underlying theories of inter-organizational relationships can be named as: (1) transaction cost, (2) resource dependency, (3) strategic choice, (4) stakeholder theory, (5) organizational theory, and (6) institutional theory (Barringer \& Harrison, 2000). However, there are two theories, which are dominant in the literature, namely, TCT and RBV. These two theories are complementary, and a hybrid of them can be advantageous as both. Although, hybrid of these two theories is proposed by many authors, but it is not applied in a practical model yet. Moreover, the fit theory was selected as perquisite of any success in alliances, whereas in unfit situations the failure of the alliance is quite likely.

The resource-based view: The resource-based view is one of the most important theories in strategic alliance justification. Resource-based view is an inward-looking approach which emphasizes internal resources as the main origin of competitive advantage (Teece et al., 1997). In this view, firms are a complex bundle of tangible and intangible resources, and firms' performance is a function of its resource possession, thus resources are the main origin of firm's competitive advantages (Das \& Teng, 2000). The resource-based view was introduced by Wernerfelt (1984) and developed by Barney (1991) which introduces VRIO/N framework. The noticeable works in RBV can be listed as (Grant, 1991; 
Helfat \& Peteraf, 2003; Javidan, 1998; Peteraf, 1993; Prahalad \& Hamel, 1990; Tampoe, 1994; Wang et al., 2012).

Based on our knowledge, the resource-based theory was, first, employed for justification of strategic alliances by Eisenhardt and Schoonhoven (1996). They provide a new explanation of alliance formation in a longitudinal study and consider the social and strategic aspects of the problem. Then, Das and Teng (2000) try to provide a general RB theory of strategic alliance. Furthermore, there are some efforts on the partner selection based on resource-based view. Hitt et al. (2000), discuss the critical success factors of partner selection based on RB in emerging and developed countries. Similarly, Hitt et al. (2004) discuss the Institutional Effects of Partner Selection in China and Russia as Transition Economies. In the following, Huang et al. (2005) and Emden et al. (2006) discuss the issue in resource allocation and new-product development fields. In more recent works, two review papers are noticeable, EspinoRodríguez and Padrón-Robaina (2006) review the outsourcing problem from the resource-based view and Jiang (2011) review the theoretical aspects of strategic alliances consists of RB and TC theories.

Transaction cost theory: The transaction-cost theory has been widely used throughout the literature for justification of inter-organizational issues as one of the oldest theories (Dyer, 1997; Madhok \& Tallman, 1998; Williamson, 1991). The TC theory declares that the firms' boundaries specified in order to minimize the sum of production and transaction costs (traditional "make or buy question?"), and the inter-organizational relationship is a way to decline the market uncertainties and reduce of total costs (Barringer \& Harrison, 2000). The transaction cost refers to cost of activities like writing, enforcing and monitoring contracts and production cost refers to the cost of producing, organizing and managing. The TCT argues that the internalization is preferred choice in situations of low production costs and high transaction costs. The transaction cost is high when there is a high rate of opportunistic behavior and high asset specificity. The externalization is preferred choice when there are high production costs are and low transaction costs. Accordingly, the allying is feasible when the firm face with medium transaction and production costs, and transaction costs are not high enough to justify internalization (Tushar \& Teng, 2000). Furthermore, TCT theory was used in phase of partner/alliance selection, for example, Li and Ferreira (2008) discuss partner selection in international strategic alliances and explore the alliances of US corporations in emerging countries. They employ TCT theory for justification purposes. Cetkovic et al. (2016) discuss the use of TC theory in determining of alliance organizational structure and design. Ang (2007) discuss the role of partner alignment in the choice of equity or nonequity alliance structure and find that results are in conformity with TC rationale.

Conclusively, there is a handful of papers, which employ both theories. Tsang (2000) explains the role of the resource-based view and transaction-cost theory in the formation of joint ventures and compares them. They analyzed the problem and develop six theoretical propositions. Furthermore, Chen and Chen (2003) discuss the relevance of the resource-based view and transaction cost theory in alliance structure. They find the transaction-cost more suitable for choice between contractual alliances and joint ventures, and resources-based, more appropriate for choosing between a different kind of contractual alliances. Moreover, Yasuda (2005) compares the two theories of resource-based view and transaction-cost, of their power in justification of strategic alliance formed in high-tech environment. They employ empirical analysis in semi-conductor industry and find the resource-based view as a dominant theory. Finally, Holcomb and Hitt (2007) discuss the outsourcing problem from the resourcebased and transaction cost point of view. Although the scholars emphasized on the complementarity of TCT and RBV theories, but there is a lack of an integrative approach in the "strategic alliance partner choice and evaluation" problem. The previous works tried to compare two theories (Tsang, 2000; Yasuda, 2005) or tried to extend them in a specific area (Holcomb \& Hitt, 2007). Explaining the complementary of them, the TCT concentrates on minimizing of cost based issue's whiles RBV focus on maximizing the value of each firm in the alliance. TCT tries to economize transaction and production costs and presents proper governance structure, while RBV tries to maximize profits in the long-term by exploiting and developing resources. Moreover, TCT proposes to ally when transaction costs are not so high and take an intermediate place, whilst RBV proposes to ally when critical resources -owned by other firms - are inseparable from other resources of the owner. In addition, TCT can consider 
opportunistic behavior of firms, which occurs in specific circumstances, and proposes useful statements that could not be found in RBV. Furthermore, TCT assumes that all firms can produce or offer services equally effective and this weakness could be compensated by incorporating RBV, because in RBV each firm's performance determined by its complex bundle of resources and RBV explicitly differentiae firms in their performance (Das \& Teng, 2000; Holcomb \& Hitt, 2007; Salamat et al., 2016; Tsang, 2000; Williamson, 1999). Generally speaking, each of the theories has some weaknesses, which can be compensated in new integrative approach. Thus, in this paper, the focus is on the new integrated approach based on RBV, TCT and Fit theories as the theoretical foundation of the model.

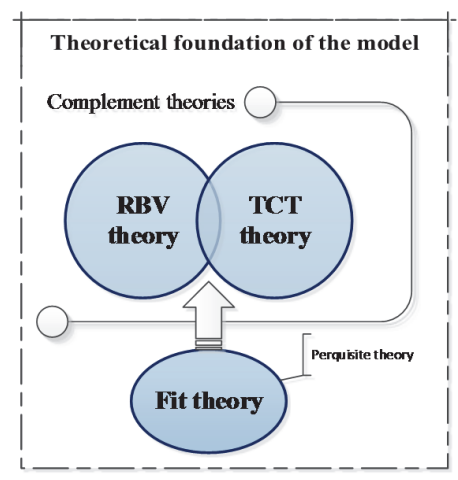

Fig. 3. Theoretical foundation of the model

Fit theory: The fit theory is an important theory of inter-organizational relationship, which emphasizes on different aspects of similarity between the two partners as the main reason of alliance success. The "fit" concept is very important in strategic alliance literature because it is an outstanding necessary condition and a critical success factor of any successful strategic alliance. Indeed, the fit is the precedence of alliance success (Douma et al., 2000). The concept of fit was discussed by many authors in alliances and strategic management literature. The authors discussed the concept of fit and alignment from a strategic viewpoint (Chorn, 1991). There are important topics in intersection of fit concept and alliance management in the literature, for example, the role of fit on the alliance partner selection (Bierly \& Gallagher, 2007; Cummings \& Holmberg, 2012), the role of strategic fit in the governance of an alliance, including contractual and procedural governance (Nielsen, 2010), and the impact of configurational fit on the success of international SME alliances (Swoboda et al., 2011), and the concept of fit in the value added network (Nee et al., 2013). In sum, the theoretical foundation of the model and is illustrated in Fig 3.

\section{The assessment criteria}

The assessment criteria were used based on the three above mentioned theories of RBV, TCT and Fit theory. In the $R B V$ theory, the two criteria of uniqueness and collectiveness were selected for assessment. These criteria were extracted from the work by Hafeez et al. (2007). They argue that the resources with two important criteria of uniqueness and collectiveness can provide sustainable competitive advantages. Uniqueness shows the distinctiveness and solitary of the firm's resources and collectiveness shows that the they are expanded in the firm, and their foot-mark can be found in products/services. Uniqueness measured by three sub-criteria, (1) rareness, (2) inimitability, and (3) non-substitutability. Similarly, Collectiveness evaluate capabilities' extent of the organization in three ways, (1) across-product, (2) across-function, and (3) across-business.

In the TCT theory, the two criteria of production cost and transaction cost are selected. Transactioncosts indicate by three sub-criteria of contracting, controlling and transforming cost. In this way, the sub-criteria of production cost include direct and indirect production cost. 


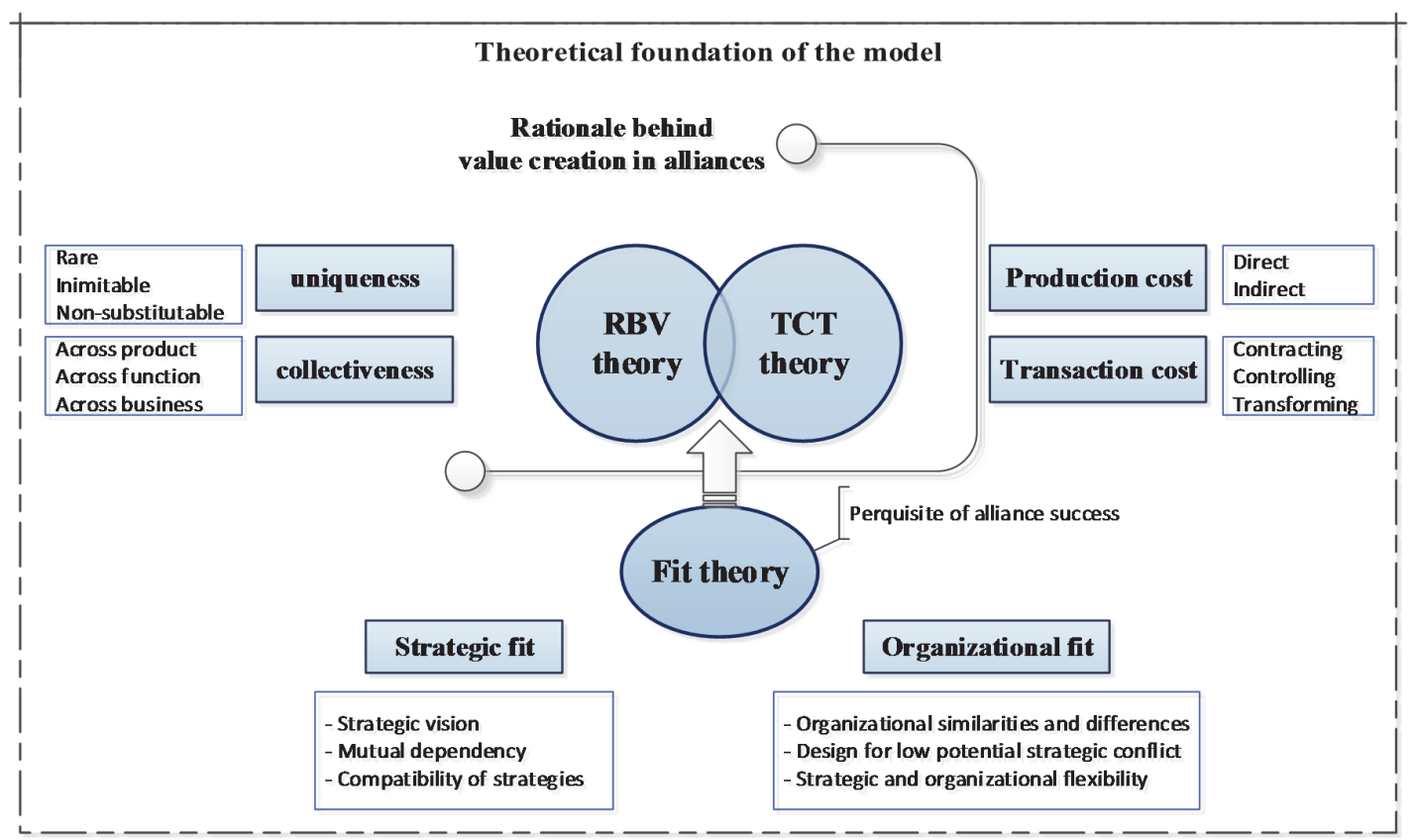

Fig 4. The theories and assessment criteria in the conceptual framework

In the fit theory, the criteria were selected based upon the framework proposed by Douma et al. (2000). They classified the fit concept -based on an in-depth case study- to strategic fit and organizational fit; where a strategic fit measured by six drivers, namely, (1) shared strategic vision for the development of alliances, (2) compatible corporate and alliance strategies, (3) strategic importance of alliance to partners, (4) mutual dependence of partners, (5) added value of alliance for clients and partners, (6) market acceptance of alliance. Accordingly, organizational fit measured by six drivers, (1) consideration of similarities and differences in alliance design, (2) strategic \& organizational flexibility in alliance design, (3) low complexity of alliance design, (4) alliance design for effective management control of partners, (5) alliance design for overcoming strategic conflicts, (6) alliance design in order to enable the partners to achieve the strategic objectives. The theories, criteria and sub-criteria are illustrated in Fig 4.

\section{The analytical approach}

The analytical approach is based on AHP technique (Saaty, 1977) and the criteria introduced in the previous section. A novel Robust Fuzzy Possibilistic AHP approach is designed as the analytical approach. As the employed criteria and sub-criteria are subjective and theory-based, so the experts face with an inherent ambiguity when they want to make the pairwise judgements. Thus, determination of an accurate point as pairwise judgements is not easy and experts prefer to provide intervals and impose the inherent ambiguity to the solution method. Although, the Robust Programming is a new way of handling uncertainty and applied to many decision making problems, including MODM and MADM techniques, but it is not applied to AHP technique and there is no solution for Robust AHP yet. Accordingly, in this section the Robust Fuzzy Possibilistic AHP approach is proposed. In the first part, the proposed approach is introduced and in the second part the numerical results discussed. The results show the advantageous of the proposed approach and illustrate that it is the best approach based on error indicators.

\subsection{The Robust Fuzzy Possibilistic AHP approach}

Robust programming provides risk-averse solutions and tries to handle the problem uncertainty. The first effort in robust programming was done by Soyster (1973) which provide a worst-case robust programming method. Also, Inuiguchi and Sakawa establish the first efforts in robust fuzzy 
mathematical programming (Inuiguchi \& Sakawa, 1995, 1998). Then, Mulvey et al. (1995) presented scenario-based programming models. In the following, an outstanding step up was developed by BenTal and Nemirovski $(1998 ; 2000)$ and El Ghaoui et al. (1998) where they employed different convex uncertainty sets in uncertain linear problems. In more recent years, a less conservative approach was presented by Bertsimas and Sim (2004) in the category of worst case formulations. There are other less important approaches which omitted here for the sake of brevity. In addition, the robust approaches were applied extensively in practical applications, for example, (Adida \& Perakis, 2006; Beyer \& Sendhoff, 2007; Ghaoui et al., 2003; Maries \& Scarlat, 2012; Östermark, 2005, 2011; Pan \& Nagi, 2010; Pishvaee et al., 2011; Zhu et al., 2011). Generally speaking, the robust programming approaches classified into three main categories, 1) hard worst case approach, 2) soft worst case approach, and 3) realistic approach (Pishvaee et al., 2012). These three approaches are different in their safety against uncertain parameters, where the hard worst case provides maximum immunity in the face of uncertainty. In other words, the obtained solution is feasible in all values of uncertain parameter or in the worst-case scenario. The soft worst case approach is more flexible and don't rely on the satisfaction of all constraints in their worst-case value, and some degree of violation is possible. Finally, the realistic approach tries to tradeoff between robustness and cost of robustness in a cost-benefit logic. In this approach, violation of constraint by their worst-case value is allowed, and model seeks for a good relative robust solution which is near to optimal and also feasible in majority of values of uncertain parameters.

The robustness of a solution is defined by two important characteristics, namely, optimality robustness and feasibility robustness. A solution which has feasibility robustness should maintain its feasibility for (almost) all possible values of uncertain parameters. Also, optimality robustness occurred when the value of objective function has a minimum deviation from the optimal value for (almost) all possible values of uncertain parameters. According to this concept, there are no scientific efforts on robust modeling of the AHP technique. Although, Lipovetsky and Conklin (2002) proposed a formulation for robust estimation of weights in AHP, but his method tries to identify false data and no solution was proposed for calculation of weights. The robust concept makes sense in the interval AHP, when the decision makers are not confident of his preferences and provide intervals for comparison matrix.

In order to robustly formulate the interval AHP, it is essential to understand the common model of the interval AHP. One of the first efforts was done by Arbel (1989). He proposes a Preference Programming (PP) model, but his model was not valid for inconsistent matrices. Thus, Islam et al. (1997) provide a Goal Programming (GP) model, which was usable in inconsistent preferences. One of the most famous and efficient models is proposed by Mikhailov (2004). He proposes a Fuzzy Programming Method (FPM) which solves both consistent and inconsistent pairwise matrices in an easy and efficient formulation. The FPM model was presented in two linear and non-linear forms. After that, Chen and $\mathrm{Xu}$ (2015) extend the FPM model and tried to improve it. They argue that FPM model provides different weights from two equivalent upper or lower triangular pairwise matrices and tried to solve this drawback. Furthermore, Chandran et al. (2005) proposed a linear programming model which can be used as a substitute of common AHP solution -like eigenvector- and can be used in an interval AHP by some changes. The optimization problems (1) -(5) show the formulation of the four most important techniques.

\section{FPM- linear:}

\section{$\max \lambda$}

s.t.

$d_{i j} \lambda+w_{i}-u_{i j} w_{j} \leq d_{i j}$

$d_{i j} \lambda-w_{i}+l_{i j} w_{j} \leq d_{i j}$

$i=1.2 . \ldots . n-1 ; j=2.3 . . . n ; j>i$

$\sum_{l=1}^{n} w_{l}=1 . w_{l}>0 . \quad l=1.2 \ldots . n$

PP:
FPM- non linear:

(1) $\max \lambda$

s.t.

$p_{i j} w_{j} \lambda+\left(l_{i j}-p_{i j}\right) w_{j}-w_{i} \leq 0$

$p_{i j} w_{j} \lambda-\left(u_{i j}+p_{i j}\right) w_{j}+w_{i} \leq 0$

$i=1.2 . . . n-1 ; j=2.3 . . . n ; j>i$

$\sum_{l=1}^{n} w_{l}=1 ; w_{i}>0 ; l=1.2 . \ldots n$ 


$$
\begin{aligned}
& \max w_{i} \\
& \text { s.t. } \\
& w_{i}-u_{i j} w_{j} \leq 0 \\
& -w_{i}+l_{i j} w_{j} \leq 0 \\
& i=1.2 . \ldots . n-1 . j=2.3 . \ldots . n . j>i \\
& \sum_{l=1}^{n} w_{l}=1 ; w_{l}>0 \quad l=1.2 . \ldots . n \\
& \min w_{i} \\
& \text { s.t. } \\
& w_{i}-u_{i j} w_{j} \leq 0 \\
& -w_{i}+l_{i j} w_{j} \leq 0 \\
& i=1.2 . . . n-1 ; j=2.3 . . . n ; j>i \\
& \sum_{l=1}^{n} w_{l}=1 ; w_{i}>0 ; l=1.2 . . . n
\end{aligned}
$$

(3)

$$
\begin{aligned}
& \min \sum_{i=1}^{n-1} \sum_{j=i+1}^{n}\left(p_{i j}+q_{i j}\right) \\
& \text { s.t. } \\
& w_{i}-l_{i j} w_{j}+q_{i j} \geq 0 \\
& w_{i}-u_{i j} w_{j}-p_{i j} \leq 0 \\
& i=1.2 \ldots . n-1 ; j=i+1 . \ldots . n \\
& \sum_{l=1}^{n} w_{l}=1 . i=1.2 \ldots . n \\
& w_{i} . p_{i j} . q_{i j} \geq 0 \text { for all } i . j
\end{aligned}
$$

In order to develop Robust Fuzzy Possibilistic AHP approach, the realistic approach was selected. As in an inconsistent pairwise comparison matrix it is not possible to satisfy all constraint, the employment of hard worst case approaches is impossible. A realistic approach is capable of adjusting the degree of robustness, by model's parameters and also can manage violence of constraints in the inconsistent pairwise comparison matrix. In realistic approach, it is completely possible that some constraints violated, especially in inconsistent pairwise matrices. In addition, the FPM model was selected as the base model (Mikhailov, 2004). It is because the FPM has the best functionality and effectiveness while it is very easy to apply, and recent models cannot provide a significant step forward.

Robust Possibilistic Programming (RPP) model (Pishvaee et al., 2012) was selected as robust approach and the proposed model named as "Robust Fuzzy Possibilistic AHP" approach. The RPP is one of the most-recent robust realistic approaches, which can easily adapt the problem structure. The RPP strongly can meet the problem requirement, and it is completely flexible and it can be used instead of a range of methods from the worst case to realistic ones. This flexibility enables it to provide the best solutions in both consistent and inconsistent matrices simultaneously. The RPP model formulation is illustrated in Eq. (6) and Eq. (7).

The first term in Eq. (7) (objective function) is the expected value of basic objective function (Z). The second term, $\delta\left(Z_{\max }-Z_{\text {min }}\right)$ tries to minimize the maximum deviation of the basic objective function (Z). This term manages the optimality robustness of the solution. The third term, $\left[d_{(4)}-(1-\alpha) d_{(3)}-\right.$ $\left.\alpha d_{(4)}\right]$ control the feasibility robustness and penalize the objective function by the unit of violation in each constraint. The parameter $\alpha$ show the confidence level of each constraint and show the degree of constraint satisfaction. The parameters $\delta$ and $\sigma$ can be used to trade-off between cost of robustness and the degree of robustness.

\section{Basic model: \\ $\operatorname{Min} Z$ \\ $=\tilde{f} y+\tilde{c} x$ \\ subject to \\ $A x \geq \tilde{d}$ \\ $S x \leq N y$ \\ $B x=e$ \\ $y \in\{0.1\} . x \geq 0$}

$$
\begin{aligned}
& \text { Robust model: } \\
& \begin{array}{l}
\text { Min } E[Z]+\delta\left(Z_{\text {max }}-Z_{\text {min }}\right) \\
\qquad+\sigma\left[d_{(4)}-(1-\alpha) d_{(3)}-\alpha d_{(4)}\right]
\end{array} \\
& \text { subject to } \\
& \begin{array}{l}
A x \geq(1-\alpha) d_{(3)}+\alpha d_{(4)} \\
S x \leq N y \\
B x=e \\
y \in\{0.1\} . x \geq 0
\end{array}
\end{aligned}
$$


The interval AHP imposes two important constraints as: $l_{i} \leq \frac{W_{i}}{W_{j}} \leq U_{i}$. This constraint shows the main logic in the interval AHP. In other words, the DM will be satisfied with the solutions' ratio inside the interval and dissatisfied, otherwise. In the FPM method, this logic was changed in a fuzzy way so that the DM was most satisfied in the middle of the interval, and his dissatisfaction will increase when the solution ratio gets far from the interval. So the degree of satisfaction in membership function can be greater than one in the middle of the interval and can be negative outside of the interval. The membership function of FPM method is shown in Eq. (8), where $m_{i j}$ is the middle of $\left[l_{i j}\right.$. $\left.u_{i j}\right]$ interval and $d_{i j}$ is the tolerance parameter for the considered interval; $d_{i j}=u_{i j}-l_{i j}$ or $d_{i j}=1$; (Mikhailov, 2004).

$$
\mu_{i j}^{L}\left(w_{i} \cdot w_{j}\right)=\left\{\begin{array}{l}
1-\frac{\left(-w_{i}+l_{i j} w_{j}\right)}{d_{i j}} \cdot \frac{w_{i}}{w_{j}} \leq m_{i j} \\
1-\frac{\left(w_{i}-u_{i j} w_{j}\right)}{d_{i j}}, \frac{w_{i}}{w_{j}} \geq m_{i j}
\end{array}\right.
$$

The FPM formulation extract from the miximin prioritization of the above membership function as illustrate in Eq. (9)

$$
\mu_{P}\left(W^{*}\right)=\max _{w \in Q^{n-1}} \min _{i j}\left\{\mu_{i j}(w)\right\}
$$

Following fuzzy mathematical programming, the above formula can be rewrite as Eq. (10):

$$
\begin{aligned}
& \max \lambda \\
& \text { subject to } \\
& \lambda \leq \mu_{i j}(w) \\
& i=1.2 . . . . n-1 ; j=2.3 . . . . n ; j>i
\end{aligned}
$$

Based on different membership functions in Eq. (10), two different linear and nonlinear fuzzy programming formulations can be obtained, as illustrated in Eq. (1) and Eq. (2). Applying RPP model on Mikhailov FPM model, the following formula will be obtained:

\section{RFPA model:}

$\max P=\lambda-\mathrm{\gamma}\left[\sum_{i=1}^{n-1} \sum_{j=i+1}^{n}\left(y_{i j}+z_{i j}\right)+\sigma \sum_{i=1}^{n-1} \sum_{j=i+1}^{n}\left(y^{\prime}{ }_{i j}+z^{\prime}{ }_{i j}\right)\right]$

subject to

$\sum_{l=1}^{n} w_{i}=1$

$y_{i j} \geq w_{i}-u_{i j} w_{j}$

$$
i=1.2 . \ldots . n-1 ; j=2.3 . \ldots . n ; j>i
$$

$z_{i j} \geq-w_{i}+l_{i j} w_{j}$

$$
i=1.2 \ldots . n-1 ; j=2.3 . . . n ; j>i
$$

$y_{i j}^{\prime} \geq w_{i}-u_{i j} w_{j}-d_{i j}$

$$
i=1.2 . \ldots . n-1 ; j=2.3 . \ldots . n ; j>i
$$

$z^{\prime}{ }_{i j} \geq-w_{i}+l_{i j} w_{j}-d_{i j}$

$$
i=1.2 . \ldots . n-1 ; j=2.3 . \ldots . n ; j>i
$$

$d_{i j} \lambda+w_{i}-u_{i j} w_{j} \leq d_{i j}$

$i=1.2 . \ldots . n-1 ; j=2.3 . . . n ; j>i$

$d_{i j} \lambda-w_{i}+l_{i j} w_{j} \leq d_{i j}$

$$
i=1.2 . . . n-1 ; j=2.3 . . . n ; j>i
$$

$y_{i j} \cdot z_{i j} \cdot y_{i j}^{\prime} \cdot z_{i j}^{\prime} \geq 0$.

$$
w_{i}>0 . i . j=1.2 \ldots . n ; l=1.2 . \ldots . n
$$

The three terms of RPP were demonstrated in Eq. (11). The second term of RPP is not applicable because the objective function has not any uncertain parameter. The third term of RPP is completely reflected in the term $\gamma\left[\sum_{i=1}^{n-1} \sum_{j=i+1}^{n}\left(y_{i j}+z_{i j}\right)+\sigma \sum_{i=1}^{n-1} \sum_{j=i+1}^{n}\left(y_{i j}^{\prime}+z^{\prime}{ }_{i j}\right)\right]$. This term is related to 
first-order $l_{i} \leq \frac{W_{i}}{W_{j}} \leq U_{i}$, and second order constraints $\left(l_{i j}-d_{i j} \leq \frac{W_{i}}{W_{j}} \leq U_{i j}+d_{i j}\right)$. First-order constraints reflected in Eqs. (13)-(14) and variables $y_{i j}$ and $z_{i j}$ in the objective function. Second-order constraints reflected in Eqs. (15)-(16) and variables $y^{\prime}{ }_{i j}$ and $z^{\prime}{ }_{i j}$ in the objective function. The Eqs. (17) -(18) have been obtained from applying Mikhailov's Eqs. (8) in Eq. (10). The Robust Fuzzy Possibilistic AHP model was obtained after some variable changes that made it simpler. It is notable that the model can handle any inconsistent matrices without infeasible error. Indeed, the objective function penalized by violation of first and second order constraints and the parameter $\sigma$ shows the relative weight of them, which is greater than one. This parameter causes the solution ratios place leastwise in second order constraints. The performance of the proposed model is compared with FPM, PP, GP and NFPM model. Five indicators were selected for comparison of the methods: 1) $D_{1}=$ $\frac{\sum_{j} \sum_{i} r_{i j}}{n(n-1) / 2}$, 2) $\left.D_{2}=\frac{\sum_{j} \sum_{i} r_{i j}^{\prime}}{n(n-1) / 2}, 3\right) D_{3}=\sum_{j} \sum_{i} e_{i j}$, 4) $\left.D_{4}=\sum_{j} \sum_{i} e_{i j}^{\prime}, 5\right) \mu_{P}(w)=\sum_{i=1}^{n} \sum_{j=i+1}^{n} \mu_{i j}(w) . D_{1}$ and $D_{2}$ show the percentage of first and second order constraint violations, where $r_{i j}$ is binary variables, equal to one when the solution ration $w_{i} / w_{j}$ violate the interval $\left[l_{i j} . u_{i j}\right]$, also $r_{i j}^{\prime}$ is binary and is one in the violation of second order constraints. $D_{3}$ and $D_{4}$ are the sum of out of intervals distances. In other words, $e_{i j}$ and $e_{i j}^{\prime}$ determine the distance from one side of the first order or second order intervals, where, $\quad e_{i j}=\max \left(w_{i} / w_{j}-u_{i j} .0\right)+\max \left(l_{i j}-w_{i} / w_{j} .0\right), \quad e_{i j}^{\prime}=\max \left(w_{i} / w_{j}-u_{i j}-d_{i j} .0\right)+$ $\max \left(l_{i j}-d_{i j}-w_{i} / w_{j} \cdot 0\right) . \mu_{P}(w)$ show the total satisfaction score (for each interval), the membership function used for calculation of $\mu_{P}(w)$ is shown in Fig 5, the satisfaction degree is equal to one between the intervals, between zero to one in second order intervals and it is negative, out of second order intervals. As long as it gets far from a second order distance, the negative number gets bigger, so it penalizes for distance from intervals. In the following, the comparison of the Robust Fuzzy Possibilistic AHP approach with other models discussed in different examples categorized in consistent, weakly inconsistent and strongly inconsistent matrices.

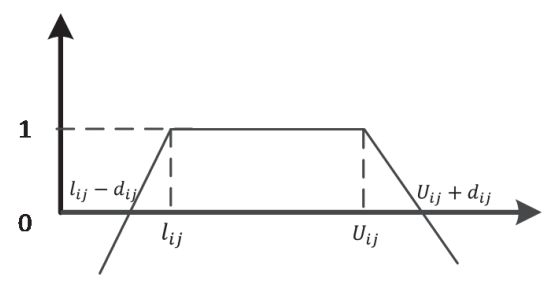

Fig 5. The membership function used in $\mu$ calculation

\subsection{The numerical results}

\section{Numerical examples- consistent judgements}

In this section, the aim is to discuss the properties of the Robust Fuzzy Possibilistic AHP approach by different types of examples. The first example (extracted from Mikhailov (2004)) is a consistent twodimensional problem, where $a_{12}=$ [1.2]. The results of different methods were depicted in Table 1 .

\section{Table 1}

Two-dimensional consistent judgement

\begin{tabular}{|c|c|c|c|c|c|c|c|c|}
\hline Method & $W_{1}$ & $W_{2}$ & $W_{1} / W_{2}$ & $D_{1} \%$ & $D_{2} \%$ & $D_{3}$ & $D_{4}$ & $\mu_{P}(w)$ \\
\hline FPM- linear $; d(i, j)=1$ & 0.6 & 0.4 & 1.5 & 0 & 0 & 0 & 0 & 1 \\
\hline FPM; linear ; $d(\mathrm{i}, \mathrm{j})=\mathrm{u}-\mathrm{l}$ & 0.6 & 0.4 & 1.5 & 0 & 0 & 0 & 0 & 1 \\
\hline FPM; nonlinear ; $d(i, j)=1$ & 0.6 & 0.4 & 1.5 & 0 & 0 & 0 & 0 & 1 \\
\hline FPM; nonlinear ; $d(i, j)=u-l$ & 0.6 & 0.4 & 1.5 & 0 & 0 & 0 & 0 & 1 \\
\hline PP & 0.583 & 0.417 & 1.4 & 0 & 0 & 0 & 0 & 1 \\
\hline GP & 0.667 & 0.333 & 2 & 0 & 0 & 0 & 0 & 1 \\
\hline RFPA; $d(i, j)=1$ & 0.6 & 0.4 & 1.5 & 0 & 0 & 0 & 0 & 1 \\
\hline RFPA; $d(i, j)=u-l$ & 0.6 & 0.4 & 1.5 & 0 & 0 & 0 & 0 & 1 \\
\hline
\end{tabular}


Obviously, the Robust Fuzzy Possibilistic AHP approach provides the best solution as same as some other methods. The solution which satisfies the interval and place exactly in the middle of the interval. Robust Fuzzy Possibilistic AHP approach and FPM provide the best solution in comparison with others. The second example adapted from Chen and $\mathrm{Xu}$ (2015) is a consistent three-dimensional problem as shown below. The results are shown in Table 2 .

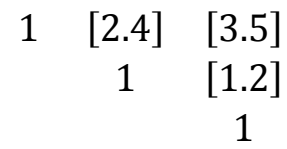

Table 2

Three-dimensional consistent judgments

\begin{tabular}{lccccccccccc}
\hline Method & $\boldsymbol{W}_{\mathbf{1}}$ & $\boldsymbol{W}_{\mathbf{2}}$ & $\boldsymbol{W}_{\mathbf{3}}$ & $\boldsymbol{W}_{\mathbf{1}} / \boldsymbol{W}_{\mathbf{2}}$ & $\boldsymbol{W}_{\mathbf{1}} / \boldsymbol{W}_{\mathbf{3}}$ & $\boldsymbol{W}_{\mathbf{2}} / \boldsymbol{W}_{\mathbf{3}}$ & $\boldsymbol{D}_{\mathbf{1}} \%$ & $\boldsymbol{D}_{\mathbf{2}} \%$ & $\boldsymbol{D}_{\mathbf{3}}$ & $\boldsymbol{D}_{\mathbf{4}}$ & $\boldsymbol{\mu}_{\boldsymbol{P}}(\boldsymbol{w})$ \\
\hline FPM-linear; d(i,j)=1 & 0.583 & 0.25 & 0.167 & 2.33 & 3.5 & 1.5 & 0 & 0 & 0 & 0 & 3 \\
FPM-linear; d(i,j)=u-1 & 0.615 & 0.231 & 0.154 & 2.66 & 4 & 1.5 & 0 & 0 & 0 & 0 & 3 \\
FPM-nonlinear; d(i,j)=1 & 0.6 & 0.24 & 0.16 & 2.5 & 3.75 & 1.5 & 0 & 0 & 0 & 0 & 3 \\
FPM-nonlinear; d(i,j)=u-1 & 0.629 & 0.219 & 0.152 & 2.87 & 4.12 & 1.43 & 0 & 0 & 0 & 0 & 3 \\
PP & 0.612 & 0.225 & 0.163 & 2.72 & 3.76 & 1.38 & 0 & 0 & 0 & 0 & 3 \\
GP & 0.667 & 0.167 & 0.167 & 4 & 4 & 1 & 0 & 0 & 0 & 0 & 3 \\
RFPA; d(i,j)=1 & 0.583 & 0.25 & 0.167 & 2.33 & 3.5 & 1.5 & 0 & 0 & 0 & 0 & 3 \\
RFPA; d(i,j)=u-1 & 0.615 & 0.231 & 0.154 & 2.66 & 4 & 1.5 & 0 & 0 & 0 & 0 & 3 \\
\hline
\end{tabular}

The third example is four-dimensional consistent matrix. The detailed was shown in Table 3.

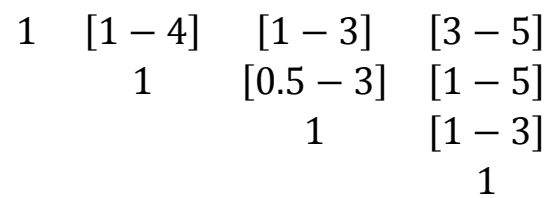

Table 3

Four-dimensional consistent judgments

\begin{tabular}{lcccccccccccccccccc}
\hline Method & $\boldsymbol{W}_{\mathbf{1}}$ & $\boldsymbol{W}_{\mathbf{2}}$ & $\boldsymbol{W}_{\mathbf{3}}$ & $\boldsymbol{W}_{\mathbf{4}}$ & $\frac{\boldsymbol{W}_{\mathbf{1}}}{\boldsymbol{W}_{\mathbf{2}}}$ & $\frac{\boldsymbol{W}_{\mathbf{1}}}{\boldsymbol{W}_{\mathbf{3}}}$ & $\frac{\boldsymbol{W}_{\mathbf{1}}}{\boldsymbol{W}_{\mathbf{4}}}$ & $\frac{\boldsymbol{W}_{\mathbf{2}}}{\boldsymbol{W}_{\mathbf{3}}}$ & $\frac{\boldsymbol{W}_{\mathbf{2}}}{\boldsymbol{W}_{\mathbf{4}}}$ & $\frac{\boldsymbol{W}_{\mathbf{3}}}{\boldsymbol{W}_{\mathbf{4}}}$ & $\boldsymbol{D}_{\mathbf{1}} \%$ & $\boldsymbol{D}_{\mathbf{2}} \%$ & $\boldsymbol{D}_{\mathbf{3}}$ & $\boldsymbol{D}_{\mathbf{4}}$ & $\boldsymbol{\mu}_{\boldsymbol{P}}(\boldsymbol{w})$ \\
\hline FPM-linear; d(i,j)=1 & 0.44 & 0.22 & 0.22 & 0.11 & 2 & 2 & 4 & 1 & 2 & 2 & 0 & 0 & 0 & 0 & 6 \\
FPM-linear; d(i,j)=u-1 & 0.42 & 0.28 & 0.19 & 0.10 & 1.48 & 2.17 & 4.11 & 1.47 & 2.77 & 1.88 & 0 & 0 & 0 & 0 & 6 \\
FPM-nonlinear; d(i,j)=1 & 0.44 & 0.25 & 0.19 & 0.11 & 1.76 & 2.23 & 3.94 & 1.26 & 2.23 & 1.76 & 0 & 0 & 0 & 0 & 6 \\
FPM-nonlinear; d(i,j)=u-1 & 0.45 & 0.24 & 0.19 & 0.10 & 1.90 & 2.39 & 4.22 & 1.25 & 2.21 & 1.76 & 0 & 0 & 0 & 0 & 6 \\
PP & 0.36 & 0.27 & 0.23 & 0.12 & 1.32 & 1.52 & 3 & 1.15 & 2.27 & 1.97 & 0 & 0 & 0 & 0 & 6 \\
GP & 0.56 & 0.14 & 0.18 & 0.11 & 4 & 3 & 5 & 0.75 & 1.25 & 1.66 & 0 & 0 & 0 & 0 & 6 \\
RFPA; d(i,j)=1 & 0.44 & 0.22 & 0.22 & 0.11 & 2 & 2 & 4 & 1 & 2 & 2 & 0 & 0 & 0 & 0 & 6 \\
RFPA; d(i,j)=u-1 & 0.42 & 0.28 & 0.19 & 0.10 & 1.48 & 2.17 & 4.11 & 1.47 & 2.77 & 1.88 & 0 & 0 & 0 & 0 & 6 \\
\hline
\end{tabular}

Three examples of consistent judgements show the applicability of the Robust Fuzzy Possibilistic AHP approach and the quality of results. In the consistent judgements the Robust Fuzzy Possibilistic AHP approach provides the solutions with zero out of interval degree according to $D_{1}$ to $D_{4}$. Moreover, Robust Fuzzy Possibilistic AHP approach tries to find solution ratios in the middle of intervals and the Robust Fuzzy Possibilistic AHP's solutions are the best in this term. Noticeably, the Robust Fuzzy Possibilistic AHP approach and FPM solve the problem similarly in consistent judgement, it is because of Robust Fuzzy Possibilistic AHP formulation, but Robust Fuzzy Possibilistic AHP's solutions are more qualitative than FPM in inconsistent judgements in terms of $D_{1}$ to $D_{4}$ as it will be discussed in the following.

\section{Numerical examples- inconsistent judgements}

In this sub-section, five inconsistent examples are discussed. Three of them are weakly, and two of them are strongly inconsistent matrices. Inconsistent judgements which have no solution ratios in the first-order intervals divide to weakly and strongly inconsistent, where weakly inconsistent matrices 
have at least one solution ratio in the second-order intervals. As Arbel's PP method is not applicable on inconsistent matrices, it is omitted here. This example is a three-dimensional weakly inconsistent judgement extracted from Mikhailov (2004). As shown in Table 4, the provided solution by Robust Fuzzy Possibilistic AHP approach is the best solution in terms of $D_{1}$ and $D_{2}$ which shows the feasibility robustness. Also, $\boldsymbol{\mu}_{\boldsymbol{P}}(\boldsymbol{w})$ is very close to optimal value, which shows that optimality robustness.

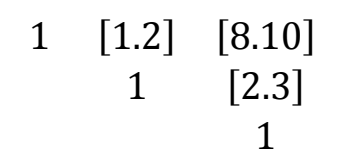

Table 4

Three-dimensional weak inconsistent judgments

\begin{tabular}{|c|c|c|c|c|c|c|c|c|c|c|c|}
\hline Method & $W_{1}$ & $W_{2}$ & $W_{3}$ & $\frac{W_{1}}{W_{2}}$ & $\frac{W_{1}}{W_{3}}$ & $\frac{W_{2}}{W_{3}}$ & $D_{1} \%$ & $D_{2} \%$ & $D_{3}$ & $D_{4}$ & $\mu_{P}(w)$ \\
\hline FPM-linear $; d(i, j)=1$ & 0.625 & 0.292 & 0.083 & 2.146 & 7.5 & 3.5 & 100 & 0 & 1.15 & 0 & 1.85 \\
\hline FPM-linear $; \mathrm{d}(\mathrm{i}, \mathrm{j})=\mathrm{u}-1$ & 0.621 & 0.293 & 0.086 & 2.118 & 7.2 & 3.4 & 100 & 0 & 1.32 & 0 & 2.08 \\
\hline FPM-nonlinear ; $d(i, j)=1$ & 0.64 & 0.276 & 0.083 & 2.317 & 7.683 & 3.317 & 100 & 0 & 0.95 & 0 & 2.05 \\
\hline FPM-nonlinear $; \mathrm{d}(\mathrm{i}, \mathrm{j})=\mathrm{u}-1$ & 0.635 & 0.279 & 0.085 & 2.275 & 7.45 & 3.275 & 100 & 0 & 1.1 & 0 & 2.18 \\
\hline GP & 0.615 & 0.308 & 0.077 & 2 & 8 & 4 & 33 & 0 & 1 & 0 & 2 \\
\hline RFPA ; d $(\mathrm{i}, \mathrm{j})=1$ & 0.615 & 0.308 & 0.077 & 2 & 8 & 4 & 33 & 0 & 1 & 0 & 2 \\
\hline RFPA $; d(i, j)=u-1$ & 0.615 & 0.308 & 0.077 & 2 & 8 & 4 & 33 & 0 & 1 & 0 & 2 \\
\hline
\end{tabular}

The next example is a $3 \times 3$ weakly inconsistent matrix extracted from Mikhailov (2004). Similar to the previous example, the Robust Fuzzy Possibilistic AHP approach provides the best solution according to $D_{1}$ and $D_{2}$ and very close to optimal value of $\boldsymbol{\mu}_{\boldsymbol{P}}(\boldsymbol{w})$ as shown in Table 5 .

$$
\begin{array}{ccc}
1 & {[1-2]} & {[0.5-1.5]} \\
& 1 & {[2-3]}
\end{array}
$$

Table 5

\begin{tabular}{|c|c|c|c|c|c|c|c|c|c|c|c|}
\hline Method & $W_{1}$ & $W_{2}$ & $W_{3}$ & $\frac{W_{1}}{W_{2}}$ & $\frac{W_{1}}{W_{3}}$ & $\frac{W_{2}}{W_{3}}$ & $D_{1} \%$ & $D_{2} \%$ & $D_{3}$ & $D_{4}$ & $\mu_{P}(w)$ \\
\hline FPM-linear- $; d(i, j)=1$ & 0.37 & 0.407 & 0.222 & 0.909 & 1.667 & 1.833 & 100 & 0 & 0.43 & 0 & 2.58 \\
\hline FPM-linear- ; $d(i, j)=u-1$ & 0.39 & 0.402 & 0.206 & 0.975 & 1.903 & 1.951 & 100 & 0 & 0.48 & 0 & 2.52 \\
\hline FPM-nonlinear $; d(i, j)=1$ & 0.362 & 0.416 & 0.222 & 0.871 & 1.629 & 1.871 & 100 & 0 & 0.39 & 0 & 2.61 \\
\hline FPM-nonlinear ; $d(i, j)=u-1$ & 0.362 & 0.416 & 0.222 & 0.871 & 1.629 & 1.871 & 100 & 0 & 0.39 & 0 & 2.61 \\
\hline GP & 0.4 & 0.4 & 0.2 & 1 & 2 & 2 & 33 & 0 & 0.5 & 0 & 2.5 \\
\hline RFPA ; $d(i, j)=1$ & 0.4 & 0.4 & 0.2 & 1 & 2 & 2 & 33 & 0 & 0.5 & 0 & 2.5 \\
\hline RFPA ; d $(\mathrm{i}, \mathrm{j})=\mathrm{u}-1$ & 0.4 & 0.4 & 0.2 & 1 & 2 & 2 & 33 & 0 & 0.5 & 0 & 2.5 \\
\hline
\end{tabular}

Three-dimensional inconsistent judgments

The sixth example is $4 \times 4$ strongly inconsistent pairwise judgement extracted from (Chen $\& \mathrm{Xu}, 2015)$. The results show the quality of the Robust Fuzzy Possibilistic AHP approach in $D_{1}, D_{2}$ and $\boldsymbol{\mu}_{\boldsymbol{P}}(\boldsymbol{w})$ as shown in Table 6. Noticeably, FPM-nonlinear $\left(d_{i j}=u\right.$-l) which has best $D_{2}\left(D_{2}=0\right)$, produce a high degree of $D_{l}$ and it forms completely out of intervals solution ratios $\left(D_{l}=100\right)$, which is not acceptable.

$$
\begin{array}{cccc}
1 & {[1-2]} & {[1-2]} & {[2-3]} \\
& 1 & {[3-5]} & {[4-5]} \\
& & 1 & {[6-8]}
\end{array}
$$


Table 6

Four-dimensional inconsistent judgments

\begin{tabular}{lllllllllllllllll}
\hline Method & $\boldsymbol{W}_{\mathbf{1}}$ & $\boldsymbol{W}_{\mathbf{2}}$ & $\boldsymbol{W}_{\mathbf{3}}$ & $\boldsymbol{W}_{\mathbf{4}}$ & $\frac{\boldsymbol{W}_{\mathbf{1}}}{\boldsymbol{W}_{\mathbf{2}}}$ & $\frac{\boldsymbol{W}_{\mathbf{1}}}{\boldsymbol{W}_{\mathbf{3}}}$ & $\frac{\boldsymbol{W}_{\mathbf{1}}}{\boldsymbol{W}_{\mathbf{4}}}$ & $\frac{\boldsymbol{W}_{\mathbf{2}}}{\boldsymbol{W}_{\mathbf{3}}}$ & $\frac{\boldsymbol{W}_{\mathbf{2}}}{\boldsymbol{W}_{\mathbf{4}}}$ & $\frac{\boldsymbol{W}_{\mathbf{3}}}{\boldsymbol{W}_{\mathbf{4}}}$ & $\boldsymbol{D}_{\mathbf{1}} \%$ & $\boldsymbol{D}_{\mathbf{2}} \%$ & $\boldsymbol{D}_{\mathbf{3}}$ & $\boldsymbol{D}_{\mathbf{4}}$ & $\boldsymbol{\mu}_{\boldsymbol{P}}(\boldsymbol{w})$ \\
\hline FPM-linear; d(i,j)=1 & 0.31 & 0.43 & 0.19 & 0.05 & 0.73 & 1.64 & 5.6 & 2.23 & 7.6 & 3.4 & 83 & 50 & 8.84 & 4.8 & 1.97 \\
FPM-linear ; d(i,j)=u-1 & 0.31 & 0.41 & 0.20 & 0.06 & 0.75 & 1.5 & 4.5 & 2 & 6 & 3 & 83 & 33 & 6.75 & 1.5 & 2.25 \\
FPM-nonlinear; d(i,j)=1 & 0.23 & 0.41 & 0.28 & 0.06 & 0.56 & 0.83 & 3.71 & 1.46 & 6.53 & 4.46 & 100 & 50 & 5.93 & 1.61 & 1.68 \\
FPM-nonlinear ; d(i,j)=u-1 & 0.25 & 0.38 & 0.2 & 0.06 & 0.65 & 0.88 & 3.82 & 1.34 & 5.82 & 4.34 & 100 & 0 & 5.43 & 0 & 2.23 \\
GP & 0.30 & 0.45 & 0.15 & 0.09 & 0.66 & 2 & 3.33 & 3 & 5 & 1.66 & 50 & 17 & 5 & 2.33 & 4.34 \\
RFPA; d(i,j)=1 & 0.30 & 0.45 & 0.15 & 0.09 & 0.66 & 2 & 3.33 & 3 & 5 & 1.66 & 50 & 17 & 5 & 2.33 & 4.34 \\
RFPA; d(i,j)=u-1 & 0.30 & 0.45 & 0.15 & 0.09 & 0.66 & 2 & 3.33 & 3 & 5 & 1.66 & 50 & 17 & 5 & 2.33 & 4.34 \\
\hline
\end{tabular}

The seventh example is $5 \times 5$ weakly inconsistent judgements. The final results as illustrated in Table 7 , show that the Robust Fuzzy Possibilistic AHP's solutions are the best solution in terms of $D_{1}$ and $D_{2}$ and also it provides optimal value of $\mu_{P}(w)$.

$$
\begin{array}{ccccc}
1 & {[0.4-0.67]} & {[0.27-0.5]} & {[0.4-0.67]} & {[0.67-1.5]} \\
& 1 & {[1.5-2.5]} & {[0.67-1.5]} & {[1.5-2.5]} \\
& 1 & {[2.5-3.5]} & {[3.5-4.5]} \\
& & 1 & {[2.5-3.5]} \\
& & & 1
\end{array}
$$

Table 7

Five-dimensional inconsistent judgments

\begin{tabular}{lccccccc} 
Method & $\begin{array}{c}F P M \text {-linear } \\
d(i, j)=1\end{array}$ & $\begin{array}{c}F P M \text {-linear } \\
d(i, j)=u-l\end{array}$ & $\begin{array}{c}F P M \text {-nonlnr } \\
p(i, j)=1\end{array}$ & $\begin{array}{c}F P M-\text { nonlnr } \\
p(i, j)=u-l\end{array}$ & GP & $\begin{array}{c}\text { RFPA } \\
\mathrm{d}(\mathrm{i}, \mathrm{j})=1\end{array}$ & $\begin{array}{c}\text { RFPA } \\
\mathrm{d}(\mathrm{i}, \mathrm{j})=\mathrm{u}-1\end{array}$ \\
\hline$D_{1} \%$ & 90 & 70 & 90 & 80 & 30 & 30 & 30 \\
$D_{2} \%$ & 0 & 10 & 0 & 0 & 0 & 0 & 0 \\
$D_{3}$ & 5.39 & 4.15 & 4.26 & 2.88 & 2.02 & 2.02 & 2.02 \\
$D_{4}$ & 0 & 0.008 & 0 & 0 & 0 & 0 & 0 \\
$\mu_{P}(w)$ & 4.61 & 5.25 & 5.74 & 6.38 & 7.98 & 7.98 & 7.98 \\
\hline
\end{tabular}

The final example is $7 \times 7$ strongly inconsistent judgements. The results as depicted in Table 8 show that the Robust Fuzzy Possibilistic AHP approach provides the best solutions in terms of $D_{1}$ and $D_{2}$ and

\begin{tabular}{|c|c|c|c|c|c|c|}
\hline \multirow{2}{*}{ Method } & \multicolumn{6}{|c|}{$G P$} \\
\hline & FPM-linear $; d(i, j)=1$ & FPM-linear $; d(i, j)=u$-l & $G P \mathrm{~d}(\mathrm{i}, \mathrm{j})=1$ & $\begin{array}{l}\mathrm{d}(\mathrm{i}, \mathrm{j})=1 ; \\
\mathrm{d}(\mathrm{i}, \mathrm{j})=\mathrm{u}-1\end{array}$ & $\operatorname{RFPA} d(i, j)=1$ & RFPA ; $d(i, j)=u-1$ \\
\hline$D_{1}$ & 71 & 71 & 52 & 52 & 52 & 52 \\
\hline$D_{2}$ & 52 & 24 & 38 & 24 & 38 & 24 \\
\hline$D_{3}$ & 24.26 & 25.28 & 23.33 & 23.33 & 23.33 & 23.33 \\
\hline$D_{4}$ & 11.82 & 2.76 & 13.75 & 8.4 & 13.75 & 8.4 \\
\hline$\mu_{P}(w)$ & 8.56 & 9.21 & 11.42 & 13.51 & 11.42 & 13.51 \\
\hline
\end{tabular}
also, it provides the best value of $\mu_{P}(w)$.

$$
\begin{array}{ccccccc}
1 & {[3-5]} & {[1.2-5]} & {[2-4]} & {[1-2]} & {[5-7]} & {[4-7]} \\
& 1 & {[3-5]} & {[4-6]} & {[0.2-2.5]} & {[2-3]} & {[0.5-2]} \\
& 1 & {[2.3-5]} & {[4-6]} & {[1.4]} & {[2.5-4]} \\
& & 1 & {[3-5]} & {[5.6]} & {[1.3]} \\
& & & 1 & {[5.8]} & {[3.7]} \\
& & & & 1 & {[2.4]}
\end{array}
$$

Table 8

7-dimensional inconsistent judgments

These examples show that the Robust Fuzzy Possibilistic AHP approach has the best results on error indicators $\left(D_{1}\right.$ to $\left.D_{4}\right)$. Although GP method provides results with a low error degree but it has an 
important weakness; as it just minimizes the errors it cannot perform well in consistent problem. As it is obvious in the consistent examples, the results of GP method placed in one end of intervals and not in the middle of the interval. Moreover, in the consistent problems the GP provides more than one solution, each in the one corner of feasible space, all with low degree of DM satisfaction. Though, the Robust Fuzzy Possibilistic AHP approach minimize the error degree simultaneously with considering the satisfaction degree. This logic enables it to provide the best results in both consistent and inconsistent judgements. Furthermore, it can consider different approaches of DMs by setting the parameters in the formulation, so it can set 1) to minimize the error of first order interval $\left(D_{1}\right.$ and $\left.D_{3}\right)$, 2 ) to minimize the error of second order intervals $\left(D_{2}\right.$ and $\left.\left.D_{4}\right), 3\right)$ to maximize the satisfaction of DMs $\left(\mu_{p}\right)$. The results show the Robust Fuzzy Possibilistic AHP approach provides the best value of error indicators and concurrently, optimal or very close to the optimal value of $\mu$. It shows the logic of robust formulation which provide feasibility robustness (depicted error indicators) and optimality robustness (depicted in $\mu$ ) by providing near to the optimal value of $\mu$.

\section{Implementation and discussion}

The proposed framework was implemented in FANAP Co, as a leading ICT company in Iran, which ranked as top private firms in ICT industry according to IMI-100 annual reports. Also, graded as the fastest growing company for some years. The core business of the FANAP has concentrated on payment solutions and services. Thus, in this study, the focus is on FANAP's establishment of a strategic alliance with an international hardware provider of payment solutions. Four alternatives were selected from the initial investigations. Three of them were selected from the Asia and one from the Europe. The alternatives were assessed by the proposed framework as explained in this section. The results reported to FANAP's managers to present it in the related committee as a decision support. The proposed partner selection framework can also be used for assessment of the alliance value during the alliance in order to keep the alliance in its initial purpose. In order to implement the proposed approach, the steps introduced in the Fig 1 were followed in FANAP attentively. First of all, internal analysis (Grant's approach), industry analysis (porter's approach) and environmental analysis (PESTLE model) were done and FANAP's competitive advantageous were determined. Then, FANAP's corporate and business strategies were planned. The next step is to define the alliance aims. Generally speaking, the firms enter to partnerships in order to: (1) to obtaining resources, (2) to retaining resources (Das \& Teng, 2000), or in order to: (1) reduce the cost of current resource usage and (2) to enhance value of current resources by acquisition of new resources (Wernerfelt, 2011). Combining these two classifications and adding the fit theory related aim, the alliance aims of FANAP defined, as it depicted in Table 9. Two alliance aims are derived from RBV, two from TCT and one aim from fit theory. Also, two of them are related to current resources and two other to targeted resources (which should be obtained through alliance).

Table 9

Determined alliance aims

\begin{tabular}{|c|c|c|c|}
\hline Category of alliance aims & The alliance aims with regard to resources & $\begin{array}{l}\text { Related } \\
\text { theory }\end{array}$ & $\begin{array}{l}\text { Resource } \\
\text { type }\end{array}$ \\
\hline $\begin{array}{l}\text { To enhance value of current } \\
\text { resources }\end{array}$ & $\begin{array}{l}\text { To enhance value of current resources in the bellow list of resources: } \\
\text { - } \quad \text { Reputable brand } \\
\text { - } \quad \text { Access to financial resources, financial strength } \\
\text { - } \quad \text { Valuable, rare, experienced, talented human resources }\end{array}$ & RBV & $\begin{array}{l}\text { Current } \\
\text { resources }\end{array}$ \\
\hline $\begin{array}{l}\text { To obtain key, valuable } \\
\text { resources }\end{array}$ & 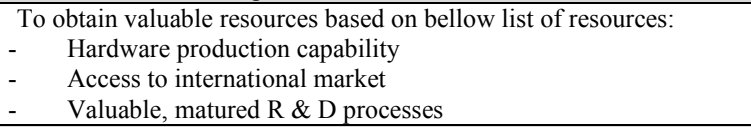 & RBV & $\begin{array}{l}\text { Targeted } \\
\text { resources }\end{array}$ \\
\hline $\begin{array}{l}\text { To minimize cost of using } \\
\text { resources }\end{array}$ & $\begin{array}{l}\text { To minimize cost of using resources in the bellow list of resources: } \\
\text { - } \quad \text { possession of various technologies in hardware and software } \\
\text { - }\end{array}$ & TCT & $\begin{array}{l}\text { Current } \\
\text { resources }\end{array}$ \\
\hline To obtain low cost resources & 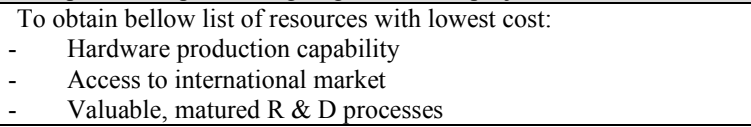 & TCT & $\begin{array}{l}\text { Targeted } \\
\text { resources }\end{array}$ \\
\hline \multicolumn{2}{|c|}{ To maintain a sustainable, long-term successful alliance } & Fit & \\
\hline
\end{tabular}


Five AHP hierarchies were designed for each of alliance aims categories. Two items of AHP hierarchies are shown in Fig 6. Then, the experts were asked for pairwise interval judgements.
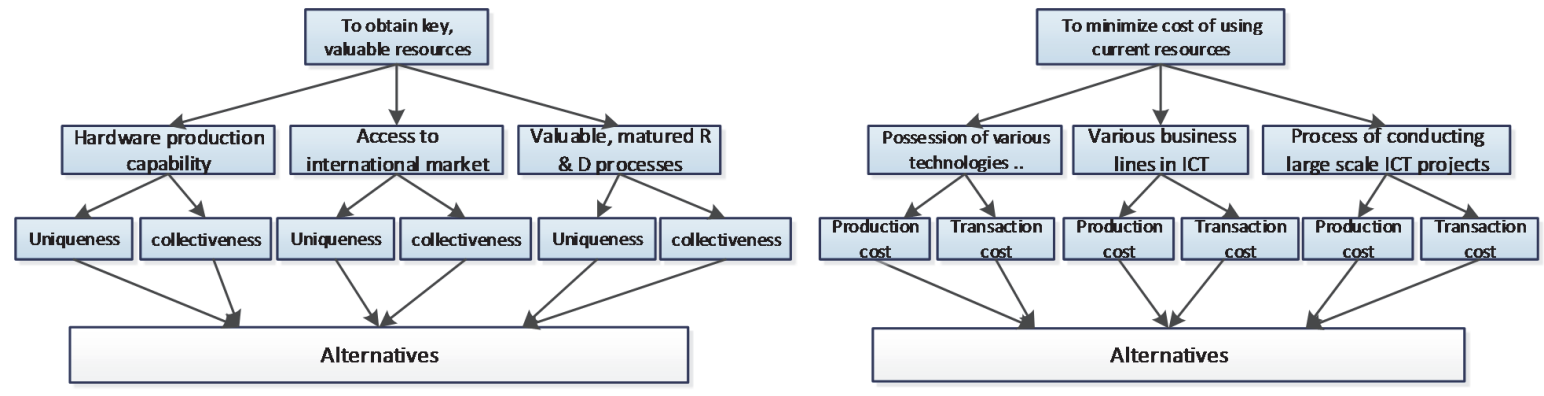

Fig. 6. AHP hierarchies of the proposed framework

For the sake of clarity, the first AHP hierarchy was explained more here. It is about the alliance's aim "to obtain key, valuable resources" which assess the targeted resources with $R B V$ theory. In the first level of hierarchy, the experts were asked to compare targeted resources according to the objective "to obtain key valuable resources." In other words, what is the relative value of resources for acquisition? In the second level of hierarchy, the relative importance of uniqueness and collectiveness was asked for each targeted resource. At the third level of hierarchy, the question to be asked is: "what is the relative importance of alternative $\mathrm{A}$ to $\mathrm{B}$ based on uniqueness for acquiring hardware production capability?" In other words, "which alternative possesses more unique hardware production capability?"

\section{Table 10}

Number of pairwise judgements with different dimensions

\begin{tabular}{lllll}
\hline $\begin{array}{l}\text { Total number of } \\
\text { pairwise judgements }\end{array}$ & $\begin{array}{l}\text { Number of } 2 \times 2 \\
\text { matrices }\end{array}$ & $\begin{array}{l}\text { Number of } 3 \times 3 \\
\text { matrices }\end{array}$ & $\begin{array}{l}\text { Number of } 4 \times 4 \\
\text { matrices }\end{array}$ & $\begin{array}{l}\text { Number of } 6 \times 6 \\
\text { matrices }\end{array}$ \\
\hline 47 & 12 & 4 & 30 & 1 \\
\hline
\end{tabular}

Accordingly, the pairwise judgements attained from the experts. Totally, 47 tables of pairwise judgments were achieved. The priority vectors were calculated by Robust Fuzzy Possibilistic AHP method. Table 10 shows the dimensions of total pairwise judgements, where $2 \times 2$ matrices are inherently consistent judgements. As shown in Table 11, there are 11 weakly inconsistent and 20 strongly inconsistent judgments. In order to show the quality of Robust Fuzzy Possibilistic AHP solutions, the Robust Fuzzy Possibilistic AHP approach was compared with two most effective approaches.

\section{Table 11}

Number of inconsistent judgements

\begin{tabular}{cccc}
\hline $\begin{array}{c}\text { Total number of } \\
\text { pairwise judgements }\end{array}$ & $\begin{array}{c}\text { Consistent } \\
\text { judgements }\end{array}$ & $\begin{array}{c}\text { Weakly inconsistent } \\
\text { judgments }\end{array}$ & $\begin{array}{c}\text { Strongly inconsistent } \\
\text { judgements }\end{array}$ \\
\hline 47 & 16 & 11 & 20 \\
\hline
\end{tabular}

The results were depicted in Table 12. In this table, $P(X) \%$ is the parentage of total inconsistent matrices in which the intended method provides the best value. Accordingly, the Robust Fuzzy Possibilistic AHP approach is the best in terms $D_{2}, D_{4}$ and $\mu$. Also, it is the best concurrently with the GP method in terms of $D_{1}$ and $D_{3}$. It is because GP directly concentrate on first order intervals and minimize its error while Robust Fuzzy Possibilistic AHP approach minimize the first order, second order and 
maximize the DM's degree of satisfaction $(\mu)$ in a robust formulation and it can manage the DM's tradeoff between these parts of the formulation.

\section{Table 12}

Performance of methods on five indicators

\begin{tabular}{llllll}
\hline Method & $P\left(D_{1}\right) \%$ & $P\left(D_{2}\right) \%$ & $P\left(D_{3}\right) \%$ & $P\left(D_{4}\right) \%$ & $P\left(\mu_{P}(w)\right) \%$ \\
\hline FPM-linear; d(i,j)=u-1 & 31 & 74 & 29 & 71 & 49 \\
GP & 97 & 74 & 91 & 66 & 77 \\
RFPA; d $(\mathrm{i}, \mathrm{j})=\mathrm{u}-1$ & 97 & 83 & 91 & 69 & 80 \\
\hline
\end{tabular}

Employing the Robust Fuzzy Possibilistic AHP method in AHP hierarchies (Table 3) leads to alternative weights as shown in Table 13. It shows that alternative 1 is the first rank in RBV, while the alternative 4 is the first rank in TCT and Fit. As described before, the fit was modeled as perquisite theory, thus, a threshold was set and alternatives with lower scores were omitted. Here, the threshold was set to 0.15 based on DM's opinion and alternative 3 was omitted.

\section{Table 13}

Weights of alternatives based on AHP hierarchies

\begin{tabular}{|c|c|c|c|c|c|}
\hline & $\mathrm{RB}$ & & $\mathrm{TC}$ & & Fit \\
\hline Alternatives & $\begin{array}{l}\text { To enhance value } \\
\text { of resources }\end{array}$ & $\begin{array}{l}\text { To obtain key } \\
\text { valuable resources }\end{array}$ & $\begin{array}{l}\text { To obtain low } \\
\text { cost resources }\end{array}$ & $\begin{array}{l}\text { To minimize cost } \\
\text { of using resources }\end{array}$ & $\begin{array}{l}\text { To maintain a sustainable, } \\
\text { long-term successful alliance }\end{array}$ \\
\hline Alternative 1 & $0.424(1)$ & $0.524(1)$ & $0.252(2)$ & $0.303(2)$ & $0.188(3)$ \\
\hline Alternative 2 & $0.133(3)$ & $0.127(4)$ & $0.104(4)$ & $0.08(4)$ & $0.245(2)$ \\
\hline Alternative 3 & $0.132(4)$ & $0.128(3)$ & $0.147(3)$ & $0.236(3)$ & $0.085(4)$ \\
\hline Alternative 4 & $0.311(2)$ & $0.221(2)$ & $0.497(1)$ & $0.381(1)$ & $0.482(1)$ \\
\hline
\end{tabular}

The final weights were measured by a combination of MIN operator and SAW method, as follows: $F W_{i}=W_{R B} \cdot \min _{i}\left(R B_{i}\right)+W_{T C} \cdot \min \left(T C_{i}\right)$. The $W_{R B}$ and $W_{T C}$ were set at 0.6 and 0.4 and final weights were calculated as shown in Table 14.

\section{Table 14}

Final weights of alternatives

\begin{tabular}{lllll}
\hline Alternatives & RB & TC & Fit & Final weights \\
\hline Alternative 1 & 0.424 & 0.252 & 0.188 & 0.3552 \\
Alternative 2 & 0.127 & 0.08 & 0.245 & 0.1082 \\
Alternative 3 & 0.128 & 0.147 & 0.085 & 0.1356 \\
Alternative 4 & 0.221 & 0.381 & 0.482 & 0.285 \\
\hline
\end{tabular}

The case study managers were asked for advantageous of the proposed framework for partner selection in practice. Some frequent points are as follows; they state that the framework provides a structured way of thinking in such a complicated problem. Moreover, the use of theories as the base of model is helpful and provide an integrated line form theories to criteria and sub-criteria. Furthermore, the use of Interval pairwise judgements instead of a single points and handling this type of uncertainty in the solution method is another significant advantageous of the framework.

\section{Conclusion}

In this paper, the problem of "choice and evaluation of strategic partner" was discussed. To address the problem, a conceptual framework and an analytical solution were introduced. In the conceptual framework, the theories of inter-organizational relationship were reviewed and three dominant theories were selected, namely, (1) Resource-based view, (2) Transaction cost theory, and (3) fit theory. The RBV and TCT were selected as justifiers of value creation logic in alliances. They are two complementary theories which cover contradictory aspects of the problem. Although, the 
complementary of two theories and advantages of a hybrid theory were discussed by many authors, but there is not any hybrid of them yet. Moreover, the fit theory was considered as the precedence of alliance success. The three theories make the theoretical foundation of the framework and criteria and sub-criteria were determined for each theory in order to assess the alternative partners.

In the analytical approach, a novel Robust Fuzzy Possibilistic AHP approach is introduced, and robust programming was used for the first time in the Interval-AHP approach in order to handle the inherent uncertainty. In this way, the PRP formulation is applied to Interval AHP and the results compared with existing methods. The result of comparisons has shown that the proposed approach could solve both consistent and inconsistent matrices by a linear and time effective formulation. Moreover, it provides Pareto optimal solutions in comparison with existing approaches; specially it is the best in terms of error degree $\left(D_{1}\right.$ to $\left.D_{4}\right)$ and satisfaction degree $(\mu)$. Furthermore, the Robust Fuzzy Possibilistic AHP approach is capable to provide all possible pareto optimal solutions with different parameter tuning and it is because of its flexible formulation. Finally, the framework implemented in a case study the results show the applicability and effectiveness of the framework. The implementation shows that the framework can help the DMs to handle the different trade-off in the problem like, (1) long-term and short term issues, (2) cost based objectives and value based objectives, (3) effectiveness and efficiency, etc. Also, the DMs confirm the benefits of framework to structure the problem in a systemic way, also to consider a logical, comprehensive and effective set of criteria. Moreover, they affirm the Robust Fuzzy Possibilistic AHP approach as a simplifier which make the comparison judgement easier and more reasonable by making it possible of interval judgements.

\section{References}

Adida, E., \& Perakis, G. (2006). A robust optimization approach to dynamic pricing and inventory control with no backorders. Mathematical Programming, 107(1-2), 97-129.

Altinay, L. (2006). Selecting partners in an international franchise organisation. International Journal of Hospitality Management, 25(1), 108-128.

Altinay, L., Brookes, M., \& Aktas, G. (2013). Selecting franchise partners: Tourism franchisee approaches, processes and criteria. Tourism Management, 37(1), 176-185.

Ang, S. H. (2007). Partner alignment and governance in IT software alliances. Journal of Computer Information Systems, 47(3), 11-16.

Arbel, A. (1989). Approximate articulation of preference and priority derivation. European Journal of Operational Research, 43(3), 317-326.

Barney, J. (1991). Firm resources and sustained competitive advantage. Journal of Management, 17(1), 99-120.

Barringer, B. R., \& Harrison, J. S. (2000). Walking a tightrope: creating value through interorganizational relationships. Journal of Management, 26(3), 367-403.

Baum, J. A., Cowan, R., \& Jonard, N. (2010). Network-independent partner selection and the evolution of innovation networks. Management Science, 56(11), 2094-2110.

Ben-Tal, A., \& Nemirovski, A. (1998). Robust convex optimization. Mathematics of Operations Research, 23(4), $769-805$.

Ben-Tal, A., \& Nemirovski, A. (2000). Robust solutions of linear programming problems contaminated with uncertain data. Mathematical Programming, 88(3), 411-424.

Bertsimas, D., \& Sim, M. (2004). The price of robustness. Operations Research, 52(1), 35-53.

Beyer, H.-G., \& Sendhoff, B. (2007). Robust optimization-a comprehensive survey. Computer Methods in Applied Mechanics and Engineering, 196(33), 3190-3218.

Bierly, P. E., \& Gallagher, S. (2007). Explaining alliance partner selection: fit, trust and strategic expediency. Long Range Planning, 40(2), 134-153.

Brookes, M., \& Altinay, L. (2011). Franchise partner selection: perspectives of franchisors and franchisees. Journal of Services Marketing, 25(5), 336-348.

Büyüközkan, G., Feyzioğlu, O., \& Nebol, E. (2008). Selection of the strategic alliance partner in logistics value chain. International Journal of Production Economics, 113(1), 148-158.

Büyüközkan, G., \& Görener, A. (2015). Evaluation of product development partners using an integrated AHP-VIKOR model. Kybernetes, 44(2), 220-237.

Cetkovic, J., Lakic, S., Knezevic, M., Zarkovic, M., \& Sazonova, T. (2016). The use of transaction costs theory in interorganizational design. Paper presented at the MATEC Web of Conferences.

Chandran, B., Golden, B., \& Wasil, E. (2005). Linear programming models for estimating weights in the analytic hierarchy process. Computers \& Operations Research, 32(9), 2235-2254.

Chang, W.-L. (2009). Using multi-criteria decision aid to rank and select co-branding partners: from a brand personality perspective. Kybernetes, 38(6), 950-965. 
Chen, H., \& Chen, T.-J. (2003). Governance structures in strategic alliances: transaction cost versus resource-based perspective. Journal of World Business, 38(1), 1-14.

Chen, L., \& Xu, Z. (2015). A new fuzzy programming method to derive the priority vector from an interval reciprocal comparison matrix. Information Sciences, 316(1), 148-162.

Chen, S.-H., Lee, H.-T., \& Wu, Y.-F. (2008). Applying ANP approach to partner selection for strategic alliance. Management Decision, 46(3), 449-465.

Chorn, N. H. (1991). The "alignment" theory: creating strategic fit. Management Decision, 29(1).

Cimon, Y. (2013). Alliances in networks: insights from blockmodeling. Kybernetes, 42(6), 955-961.

Cummings, J. L., \& Holmberg, S. R. (2012). Best-fit alliance partners: the use of critical success factors in a comprehensive partner selection process. Long Range Planning, 45(2), 136-159.

Dacin, M. T., Hitt, M. A., \& Levitas, E. (1997). Selecting partners for successful international alliances: Examination of US and Korean firms. Journal of World Business, 32(1), 3-16.

Das, T. K., \& Teng, B.-S. (2000). A resource-based theory of strategic alliances. Journal of Management, 26(1), 31-61.

Ding, J.-F., \& Liang, G.-S. (2005). Using fuzzy MCDM to select partners of strategic alliances for liner shipping. Information Sciences, 173(1), 197-225.

Doherty, A. M. (2009). Market and partner selection processes in international retail franchising. Journal of Business Research, 62(5), 528-534.

Dong, L., \& Glaister, K. W. (2006). Motives and partner selection criteria in international strategic alliances: Perspectives of Chinese firms. International Business Review, 15(6), 577-600.

Douma, M. U., Bilderbeek, J., Idenburg, P. J., \& Looise, J. K. (2000). Strategic alliances: managing the dynamics of fit. Long Range Planning, 33(4), 579-598.

Dyer, J. H. (1997). Effective interim collaboration: how firms minimize transaction costs and maximise transaction value. Strategic Management Journal, 18(7), 535-556.

Dyer, J. H., \& Singh, H. (1998). The relational view: cooperative strategy and sources of interorganizational competitive advantage. Academy of Management Review, 23(4), 660-679.

Eisenhardt, K. M., \& Schoonhoven, C. B. (1996). Resource-based view of strategic alliance formation: Strategic and social effects in entrepreneurial firms. Organization Science, 7(2), 136-150.

El Ghaoui, L., Oustry, F., \& Lebret, H. (1998). Robust solutions to uncertain semidefinite programs. SIAM Journal on Optimization, 9(1), 33-52.

Emden, Z., Calantone, R. J., \& Droge, C. (2006). Collaborating for new product development: selecting the partner with maximum potential to create value. Journal of Product Innovation Management, 23(4), 330-341.

Espino-Rodríguez, T. F., \& Padrón-Robaina, V. (2006). A review of outsourcing from the resource-based view of the firm. International Journal of Management Reviews, 8(1), 49-70.

Ghaoui, L. E., Oks, M., \& Oustry, F. (2003). Worst-case value-at-risk and robust portfolio optimization: A conic programming approach. Operations Research, 51(4), 543-556.

Glaister, K. W., \& Buckley, P. J. (1997). Task-related and partner-related selection criteria in uk international joint ventures. British Journal of Management, 8(3), 199-222.

Gomes, E., Barnes, B. R., \& Mahmood, T. (2016). A 22 year review of strategic alliance research in the leading management journals. International Business Review, 25(1), 15-27.

Grant, R. M. (1991). The resource-based theory of competitive advantage: implications for strategy formulation. California management review, 33(3), 114-135.

Gulati, R. (1998). Alliances and networks. Strategic Management Journal, 19(4), 293-317.

Gulati, R., Nohria, N., \& Zaheer, A. (2000). Strategic networks. Strategic Management Journal, 21(1).

Hafeez, K., Malak, N., \& Zhang, Y. (2007). Outsourcing non-core assets and competences of a firm using analytic hierarchy process. Computers \& Operations Research, 34(12), 3592-3608.

Hajidimitriou, Y. A., \& Georgiou, A. C. (2002). A goal programming model for partner selection decisions in international joint ventures. European Journal of Operational Research, 138(3), 649-662.

Helfat, C. E., \& Peteraf, M. A. (2003). The dynamic resource-based view: capability lifecycles. Strategic Management Journal, 24(10), 997-1010.

Hitt, M. A., Ahlstrom, D., Dacin, M. T., Levitas, E., \& Svobodina, L. (2004). The institutional effects on strategic alliance partner selection in transition economies: China vs. Russia. Organization Science, 15(2), 173-185.

Hitt, M. A., Dacin, M. T., Levitas, E., Arregle, J.-L., \& Borza, A. (2000). Partner selection in emerging and developed market contexts: Resource-based and organizational learning perspectives. Academy of Management Journal, 43(3), 449-467.

Holcomb, T. R., \& Hitt, M. A. (2007). Toward a model of strategic outsourcing. Journal of Operations Management, 25(2), 464-481.

Huang, J.-J., Tzeng, G.-H., \& Ong, C.-S. (2005). Motivation and resource-allocation for strategic alliances through the DeNovo perspective. Mathematical and Computer Modelling, 41(6), 711-721.

Inuiguchi, M., \& Sakawa, M. (1995). Minimax regret solution to linear programming problems with an interval objective function. European Journal of Operational Research, 86(3), 526-536.

Inuiguchi, M., \& Sakawa, M. (1998). Robust optimization under softness in a fuzzy linear programming problem. International Journal of Approximate Reasoning, 18(1), 21-34. 
Ireland, R. D., Hitt, M. A., \& Vaidyanath, D. (2002). Alliance management as a source of competitive advantage. Journal of Management, 28(3), 413-446.

Islam, R., Biswal, M., \& Alam, S. (1997). Preference programming and inconsistent interval judgments. European Journal of Operational Research, 97(1), 53-62.

Islam, S., Ali, M. Y., \& Sandhu, M. S. (2011). Partner selection criteria in international joint ventures: perspectives of foreign investors from Asian NIEs of Malaysia and India. Asia Pacific Business Review, 17(01), 25-43.

Javidan, M. (1998). Core competence: what does it mean in practice? Long Range Planning, 31(1), 60-71.

Jiang, X. (2011). Theoretical perspectives of strategic alliances: a literature review and an integrative framework. International Journal of Information Technology and Management, 10(2-4), 272-295.

Kavčič, K., \& Tavčar, M. I. (2008). Planning successful partnership in the process of outsourcing. Kybernetes, 37(2), 241249.

Koza, M., \& Lewin, A. (2000). Managing partnerships and strategic alliances: raising the odds of success. European Management Journal, 18(2), 146-151.

Leischnig, A., Geigenmueller, A., \& Lohmann, S. (2014). On the role of alliance management capability, organizational compatibility, and interaction quality in interorganizational technology transfer. Journal of Business Research, 67(6), 1049-1057.

Li, D., \& Ferreira, M. P. (2008). Partner selection for international strategic alliances in emerging economies. Scandinavian Journal of Management, 24(4), 308-319.

Lipovetsky, S., \& Conklin, W. M. (2002). Robust estimation of priorities in the AHP. European Journal of Operational Research, 137(1), 110-122.

Luo, Y. (1997). Partner selection and venturing success: The case of joint ventures with firms in the People's Republic of China. Organization Science, 8(6), 648-662.

MacAvoy, S. F. I. I., Robert, E., Theodore, M., Lynn, A., \& Thomas, C. (1998). Alliance management: A view from the past and a look to the future. Journal of Management Studies, 35(6), 747-772.

Madhok, A., \& Tallman, S. B. (1998). Resources, transactions and rents: managing value through interfirm collaborative relationships. Organization Science, 9(3), 326-339.

Makino, S., \& Beamish, P. W. (1999). Matching strategy with ownership structure in Japanese joint ventures. The Academy of Management Executive, 13(4), 17-26.

Maries, I., \& Scarlat, E. (2012). Computational intelligence techniques for communities network formation. Kybernetes, 41(5/6), 599-610.

Mikhailov, L. (2004). A fuzzy approach to deriving priorities from interval pairwise comparison judgements. European Journal of Operational Research, 159(3), 687-704.

Möller, K., \& Rajala, A. (2007). Rise of strategic nets-new modes of value creation. Industrial Marketing Management, 36(7), 895-908.

Möller, K., Rajala, A., \& Svahn, S. (2005). Strategic business nets - their type and management. Journal of Business Research, 58(9), 1274-1284.

Möller, K., \& Svahn, S. (2003). Managing strategic nets a capability perspective. Marketing Theory, 3(2), $209-234$.

Möller, K. K., \& Halinen, A. (1999). Business relationships and networks: managerial challenge of network era. Industrial Marketing Management, 28(5), 413-427.

Mulvey, J. M., Vanderbei, R. J., \& Zenios, S. A. (1995). Robust optimization of large-scale systems. Operations Research, 43(2), 264-281.

Nee, C., Kampker, A., \& Burggräf, P. (2013). Strategic fit assessment for value-added networks of electric engine production Advances in Sustainable and Competitive Manufacturing Systems (pp. 1323-1334): Springer.

Nielsen, B. B. (2010). Strategic fit, contractual, and procedural governance in alliances. Journal of Business Research, 63(7), 682-689.

Östermark, R. (2005). Dynamic portfolio management under competing representations. Kybernetes, 34(9/10), 1517-1550.

Östermark, R. (2011). Hedging with options and cardinality constraints in multi-period portfolio management systems. Kybernetes, 40(5/6), 703-718.

Pan, F., \& Nagi, R. (2010). Robust supply chain design under uncertain demand in agile manufacturing. Computers \& Operations Research, 37(4), 668-683.

Peteraf, M. A. (1993). The cornerstones of competitive advantage: a resource-based view. Strategic Management Journal, 14(3), 179-191.

Pishvaee, M. S., Rabbani, M., \& Torabi, S. A. (2011). A robust optimization approach to closed-loop supply chain network design under uncertainty. Applied Mathematical Modelling, 35(2), 637-649.

Pishvaee, M. S., Razmi, J., \& Torabi, S. A. (2012). Robust possibilistic programming for socially responsible supply chain network design: A new approach. Fuzzy Sets and Systems, 206(1), 1-20.

Porter, M. E. (1979). How competitive forces shape strategy.

Porter, M. E. (1980). Competitive strategies. New York.

Porter, M. E. (2008). The five competitive forces that shape strategy. Harvard Business Review, 86(1), 25-40.

Prahalad, C. K., \& Hamel, G. (1990). The core competence of the corporation. Boston (MA), 235-256.

Reuer, J. J. (1999). Collaborative strategy: The logic of alliances. Mastering strategy, 4(1), 12-13. 
Ritter, T., Wilkinson, I. F., \& Johnston, W. J. (2004). Managing in complex business networks. Industrial Marketing Management, 33(3), 175-183.

Roy, J.-P., \& Oliver, C. (2009). International joint venture partner selection: the role of the host-country legal environment. Journal of International Business Studies, 40(5), 779-801.

Roy, J. P. (2012). IJV partner trustworthy behaviour: the role of host country governance and partner selection criteria. Journal of Management Studies, 49(2), 332-355.

Saaty, T. L. (1977). A scaling method for priorities in hierarchical structures. Journal of mathematical psychology, 15(3), 234-281.

Sahebi, H., Nickel, S., \& Ashayeri, J. (2015). Joint venture formation and partner selection in upstream crude oil section: goal programming application. International Journal of Production Research, 53(10), 3047-3061.

Salamat, V. R., Aliahmadi, A., Pishvaee, M. S., \& Hafeez, K. (2016). Assessing partnership alternatives in an IT network employing analytical methods. Scientific Programming, 2016(1).

Salavrakos, I.-D., \& Stewart, C. (2006). Partner selection criteria as determinants of firm performance in joint ventures: evidence from Greek joint ventures in Eastern Europe. Eastern European Economics, 44(3), 60-78.

Schreiner, M., Kale, P., \& Corsten, D. (2009). What really is alliance management capability and how does it impact alliance outcomes and success? Strategic Management Journal, 30(13), 1395-1419.

Shah, R. H., \& Swaminathan, V. (2008). Factors influencing partner selection in strategic alliances: the moderating role of alliance context. Strategic Management Journal, 29(5), 471-494.

Solesvik, M. Z., \& Westhead, P. (2010). Partner selection for strategic alliances: case study insights from the maritime industry. Industrial Management \& Data Systems, 110(6), 841-860.

Soyster, A. L. (1973). Technical note - convex programming with set-inclusive constraints and applications to inexact linear programming. Operations Research, 21(5), 1154-1157.

Swoboda, B., Meierer, M., Foscht, T., \& Morschett, D. (2011). International SME alliances: the impact of alliance building and configurational fit on success. Long Range Planning, 44(4), 271-288.

Tampoe, M. (1994). Exploiting the core competences of your organization. Long Range Planning, 27(4), 66-77.

Teece, D. J., Pisano, G., \& Shuen, A. (1997). Dynamic Capabilities and Strategic Management. Strategic Management Journal, 18(7), 509-533.

Todeva, E., \& Knoke, D. (2005). Strategic alliances and models of collaboration. Management Decision, 43(1), $123-148$.

Tsang, E. W. K. (2000). Transaction cost and resource-based explanations of joint ventures: A comparison and synthesis. Organization Studies, 21(1), 215-242.

Wang, W., Huang, X., \& Xie, J. (2012). Study on optimizing resources configuration of value activity network of manufacturing clusters. Kybernetes, 41(7/8), 953-962.

Wassmer, U. (2010). Alliance portfolios: a review and research agenda. Journal of Management, 36(1), 141-171.

Wernerfelt, B. (1984). A resource-based view of the firm. Strategic Management Journal, 5(2), 171-180.

Wernerfelt, B. (2011). Invited editorial: The use of resources in resource acquisition. Journal of Management, 37(5), 13691373.

Williams, R., \& Lilley, M. (1993). Partner selection for joint-venture agreements. International Journal of Project Management, 11(4), 233-237.

Williamson, O. E. (1991). Comparative economic organization: the analysis of discrete structural alternatives. Administrative Science Quarterly, 36(1), 269-296.

Williamson, O. E. (1999). Strategy research: governance and competence perspectives. Strategic Management Journal, 20(12), 1087-1108.

Wiltshier, P., \& Edwards, M. (2014). Managing knowledge transfer partnership for a rural community: the outcomes at Wirksworth, UK. Kybernetes, 43(3/4), 629-651.

Wu, W. Y., Shih, H.-A., \& Chan, H.-C. (2009). The analytic network process for partner selection criteria in strategic alliances. Expert Systems with Applications, 36(3), 4646-4653.

Yasuda, H. (2005). Formation of strategic alliances in high-technology industries: comparative study of the resource-based theory and the transaction-cost theory. Technovation, 25(7), 763-770.

Young-Ybarra, C., \& Wiersema, M. (1999). Strategic flexibility in information technology alliances: the influence of transaction cost economics and social exchange theory. Organization Science, 10(4), 439-459.

Zhu, J., Gu, X., \& Gu, W. (2011). Robust optimization approach for short-term scheduling of batch plants under demand uncertainty? Kybernetes, 40(5/6), 860-870.

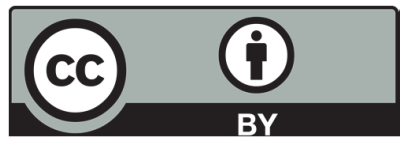

(C) 2018 by the authors; licensee Growing Science, Canada. This is an open access article distributed under the terms and conditions of the Creative Commons Attribution (CC-BY) license (http://creativecommons.org/licenses/by/4.0/). 